\title{
Cowal gold mine - documentation of slope deformations due to mining to final pit walls - a case history
}

\author{
RL Crouse Evolution Mining, Australia \\ DR Wines Itasca Australia Pty Ltd, Australia
}

\begin{abstract}
The Cowal gold mine experienced two large failures in 2007. Subsequently, an automated prism monitoring network was installed. The challenge was to be able to interpret the prism data so that small pitward movements indicative of potential failure could be identified. The problem was that the initial movement would be of the same magnitude as the survey error, and would be difficult to detect. During mining of the surficial clays and saprolites, apparent pitward movement was identified on the east pit wall. A method was needed to determine whether this movement represented the onset of failure, or was just an artefact of rebound due to mining. After mining had proceeded past the surficial clays and saprolites, prism data was downloaded, and entered into Excel spread sheets, one file per prism. The movement data was manually manipulated to remove 'jumps' of large and small scale, after which a 'best fit' line was created through the final overall movement graph. This best fit line for a series of prisms on a cross-section was entered into a different Excel graph, with the $X$-axis as time, and the $Y$-axis as initial prism elevation minus the overall change in prism movement, which had been multiplied by 500 in order to make it easier to see the movement trend. The resulting 'pseudo section' graphs showed conclusively that the pitward movement observed in the prisms located in the surficial clays and saprolites were similar, being sub-parallel to the pitward movement observed in the prisms located in the primary rock below. These graphs showed that prism movement increased and decreased as mining continued or stopped in a certain pit area. The conclusion was that all of the observed apparent movement was due to rebound due to mining, and was not an indication of impending wall failure. Three-dimensional numerical analyses were also performed using 3DEC to assess the pit movements and the future stability of the slopes.
\end{abstract}

\section{Introduction}

The Cowal gold mine is located in central New South Wales, approximately $38 \mathrm{~km}$ northeast of the town of West Wyalong, and $350 \mathrm{~km}$ west of Sydney. The mine is located on the western side of Lake Cowal, within the Bland Creek Valley. Rio Tinto Limited acquired the property in 2001, and subsequently sold the project to Homestake Mining Company the same year. Barrick acquired the project through its merger with Homestake in 2002. The mine was sold to Evolution Mining in June 2015. The mine produces approximately seven million tonnes of ore per year. The processing plant and associated infrastructure has a gravity circuit plus a conventional carbon-in-leach and cyanide leaching circuit for oxide ore, as well as a grinding, flotation, and cyanide leaching circuit for primary sulphide ore. Mine production statistics are presented in Table 1. 


\section{Table 1 Mill production statistics}

\begin{tabular}{|c|c|c|c|}
\hline Year & Tonnes & Grade $(\mathrm{g} / \mathrm{t} \mathrm{Au})$ & Ounces \\
\hline 2006 & $4,055,000$ & 1.21 & 122,000 \\
\hline 2007 & $6,615,000$ & 1.42 & 240,000 \\
\hline 2008 & $7,246,000$ & 1.06 & 192,000 \\
\hline 2009 & $7,393,000$ & 1.26 & 232,000 \\
\hline 2010 & $7,211,000$ & 1.57 & 299,000 \\
\hline 2011 & $7,034,000$ & 1.46 & 269,000 \\
\hline 2012 & $7,289,000$ & 1.39 & 267,000 \\
\hline 2013 & $7,032,000$ & 1.59 & 297,000 \\
\hline 2014 & $7,358,000$ & 1.44 & 267,000 \\
\hline Total & $61,233,000$ & 1.39 & $2,185,000$ \\
\hline
\end{tabular}

The gold deposit is located within the $40 \mathrm{~km}$ long by $15 \mathrm{~km}$ wide Ordovician Lake Cowal Volcanic Complex, east of the Gilmore Fault Zone within the eastern portion of the Lachlan Fold Belt. The ore-body is hosted in a volcaniclastic sequence informally referred to as the Lake Cowal Volcanic Complex, which includes andesite, lava, volcaniclastics, and diorites. The intrusive formations are dissected by the Cowal Fault Zone, as well as several intersecting high-angle faults with varying offsets. The orebody is a structurally-hosted, epithermal-to-mesothermal gold deposit occurring within and marginal to a $230 \mathrm{~m}$ thick diorite sill intruding trachyandesitic volcaniclastic rocks and lavas. The majority of the gold mineralisation occurs in quartz-carbonate-sulphide veins. Alteration is typically early chlorite-K-feldspar-hematite-calcite-pyrite, with a later sericite \pm ankerite assemblage associated with a base-metal-gold event. The mineralisation post-dates pre-existing faults and shears in a structural environment that produced dilational and shear veins.

Weathering of primary rock has resulted in a saprolite with a thickness of 20-50 m, with a basal saprock with a thickness of 5-10 m. Lacustrine sediments, consisting of predominantly clays, deposited in the Lake Cowal basin, cover the saprolites. The thickness of the sediments varies across the site ranging from about 10-50 m. The combined thickness of the lacustrine sediments and the saprolites is as much as $100 \mathrm{~m}$ in some places. These two units are referred to as 'surficial materials' when referring to them both.

All open pit mines experience some deformation due to mining, resulting in gradual movement of the pit walls into the excavation. The purpose of this article is to document the extent and geometry of the deformations as recorded by prism movement during mining of the Cowal pit.

\section{$2 \quad$ Pit wall deformations}

When deformation occurs in a soil or rock mass, the deformations can be classified as elastic or plastic. In theory, elastic movements occur if the strains are fully-recoverable when the loads causing the deformation are removed. Plasticity occurs when there are non-reversible changes in response to applied loads. In this case, some damage has occurred, which in a rock mass may be in the form of new fractures, movement along existing discontinuities etc. A conceptual stress-strain plot showing elastic and plastic deformations is provided in Figure 1. 


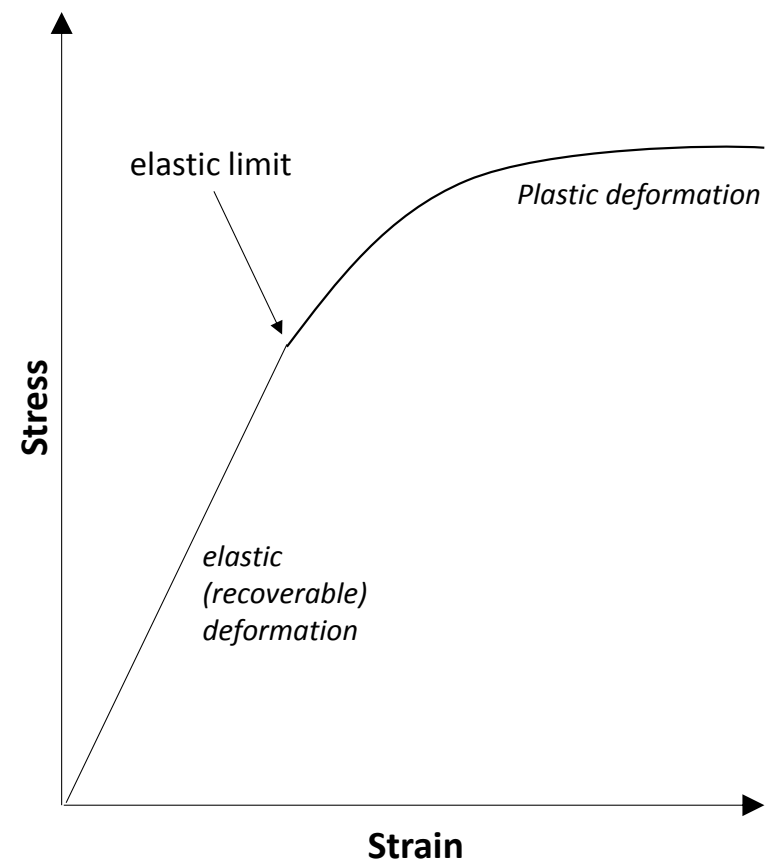

Figure 1 Stress-strain plot showing elastic and plastic deformations

Several authors have discussed the deformations that occur in pit slopes in response to excavation. This includes Zavodni (2000) and Sullivan (1993, 2007), who classify the movements based on displacement magnitudes and rates, pit depth etc. The aim of these classifications was to create systems whereby monitored displacements could be used to predict the ongoing stability of the slope. Mercer and Stacey (2008) also present a time and event dependent deformation model for rock slopes based on several case studies. Zavodni (2000) and Sullivan (2007) both refer to an initial response to excavation. Part of this initial response is the elastic movements that occur in the slope. Zavodni (2000) suggested that other factors contributing to this initial response could be relaxation and/or dilation of the rock mass due to changes in stresses induced by excavation. Sullivan (2007) suggested that total movements recorded for the initial response are in the order of 100 to $1,000 \mathrm{~mm}$.

The elastic behaviour of a soil or rock can be defined by the constants Young's modulus and Poisson's ratio. Young's modulus is the ratio of the stress along an axis to the strain along that same axis. Young's modulus varies through the loading process, and is therefore not a unique constant. Poisson's ratio is the negative ratio of transverse to axial strain. The plastic behaviour of a soil or rock mass can be defined by its strength parameters, such as cohesion, friction angle and tensile strength. For soils and intact rock, the elastic properties can be estimated based on laboratory Uniaxial Compressive Strength (UCS) testing. Empirical equations have been proposed to estimate the elastic properties for a rock mass. Hoek and Diederichs (2006) proposed the following equation to calculate Young's modulus for the rock mass ( $\left.E_{r m}\right)$ based on the Geological Strength Index (GSI), the intact Young's modulus $\left(E_{i}\right)$ and the disturbance factor (D):

$$
E_{r m}=E_{i}\left(0.02+\frac{1-D / 2}{1+e^{((60+15 D-G S I) / 11)}}\right)
$$

Hoek et al. (1995) proposed the following equation to estimate Poisson's ratio for the rock mass $\left(v_{\mathrm{rm}}\right)$ :

$$
v_{r m}=0.32-0.0015 \times G S I
$$

As expected, elastic deformations will generally include a component that is moving into the area of excavation. Numerical analyses performed by the authors also suggest that there is a slight component of uplift (upward movement) as the weight of the excavated material is removed. It is likely that this occurs in reality; however, it will be largely missed by conventional monitoring (such as prisms), because most of the uplift will probably occur prior to installation of the monitoring systems. 


\section{7 slope failures}

In 2007, two failures occurred in the surficial materials in the east side of the pit. The second failure, which was the larger of the two, started at the toe and unravelled upward towards the pit crest (Figure 2).

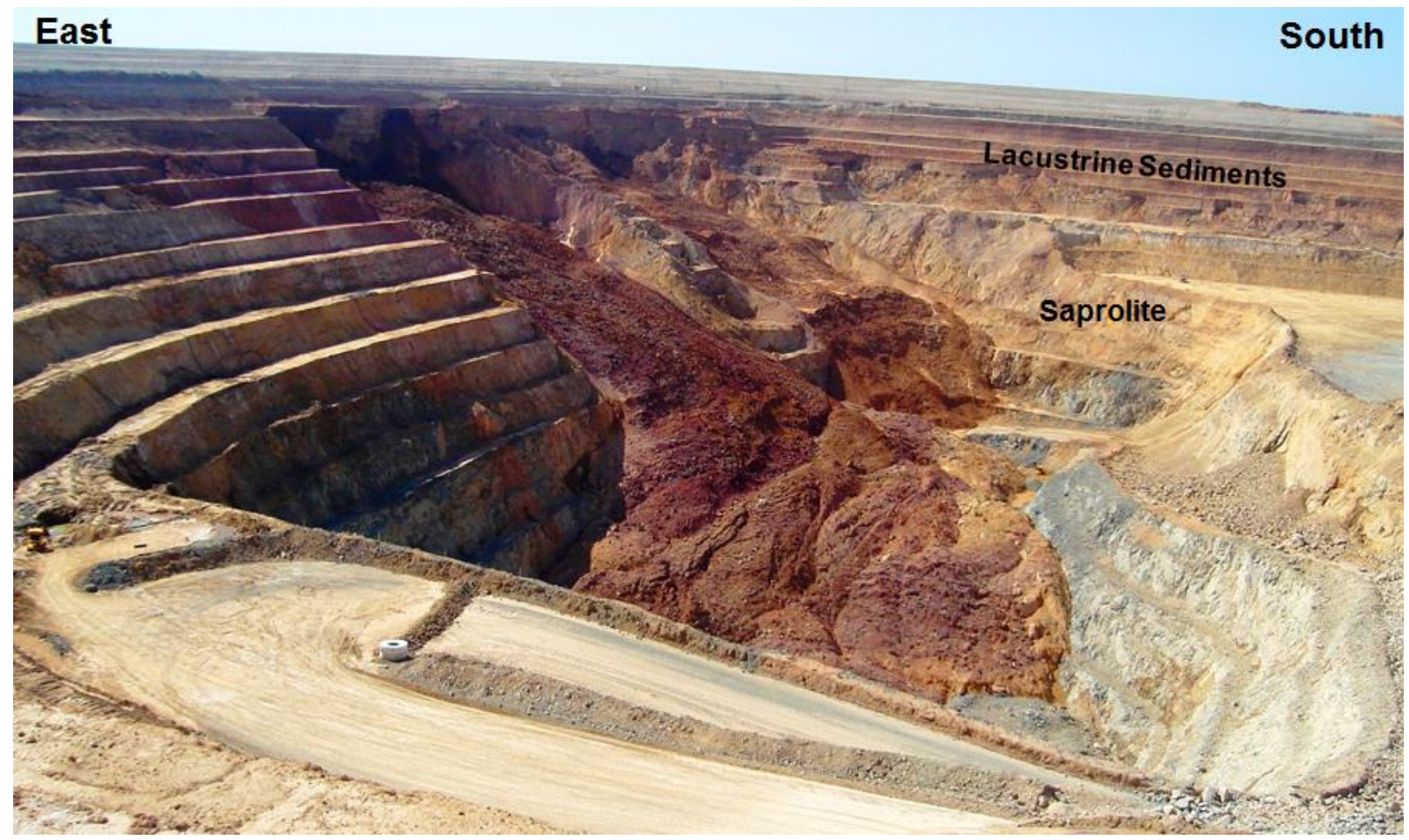

Figure 2 East wall failures - December 2007

Unfortunately, prism monitoring and movement analysis prior to the failures were not adequate to properly document the slope movement before the instability occurred. The prism coverage was very sparse, so the initial wall movement in the affected area was not recorded. The graphs in Figure 3 show the wall had experienced movement prior to the placement of the prisms.

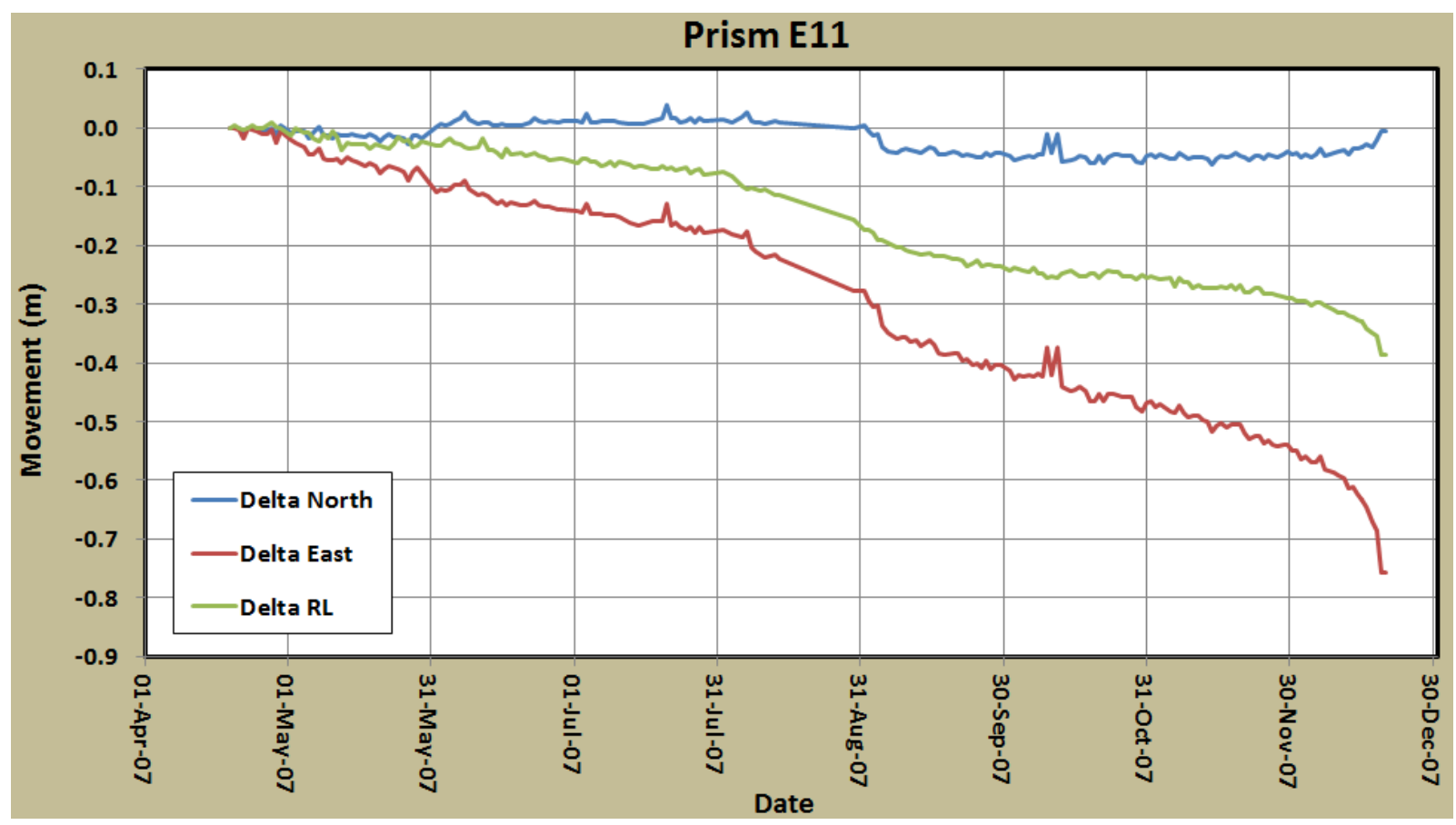

Figure 3 East wall prism movement graphs 
The 2007 failures served as the 'wake-up call' for the mine. The east wall of the pit had been mined at 31 degrees instead of the design angle of 25 degrees, the lacustrine clays and saprolites were fully-saturated and the regional stress direction was essentially east-west. All three of these factors contributed to the failures. In the next two years, the mine initiated an extensive horizontal drain drilling program and installed several automated prism monitoring stations. For the first time, prisms were set out on a relatively tight spacing around the entire pit area. With adequate monitoring in place, the next question was how much slope movement was considered to be normal, i.e. elastic and plastic deformations due to mining, and how much slope movement would indicate possible early signs of eventual failure. These are the questions that will be addressed in this paper.

\section{$4 \quad$ Automated prism monitoring data}

The automated prism survey stations were located on the pit crest, so any calculated prism movement had to take into account movement of the survey station as well as movement of the prisms being surveyed. For this reason, a satellite GPS receiver was installed at each survey station, so the movement of the survey station could be removed from the calculated prism coordinates. The survey instrument uses a laser beam to determine the slope distance from the instrument to the prisms. The changes in the individual $x-, y-$ and z-prism coordinates from the initial surveyed coordinates are the measurements that are utilised in this study. An automated prism monitoring database is seldom 'clean', meaning there are random outliers, non-random outliers, and 'jumps' in the data, all of which make it difficult to make meaningful movement graphs, especially when the prism movement is of a small magnitude. As a result, the individual prism data had to be converted to Excel data files in order to remove the outliers and 'jumps' of the data prior to graphing and analysis. An example of the raw data and corrected data for eastings are presented in Figures 4 and 5 respectively.

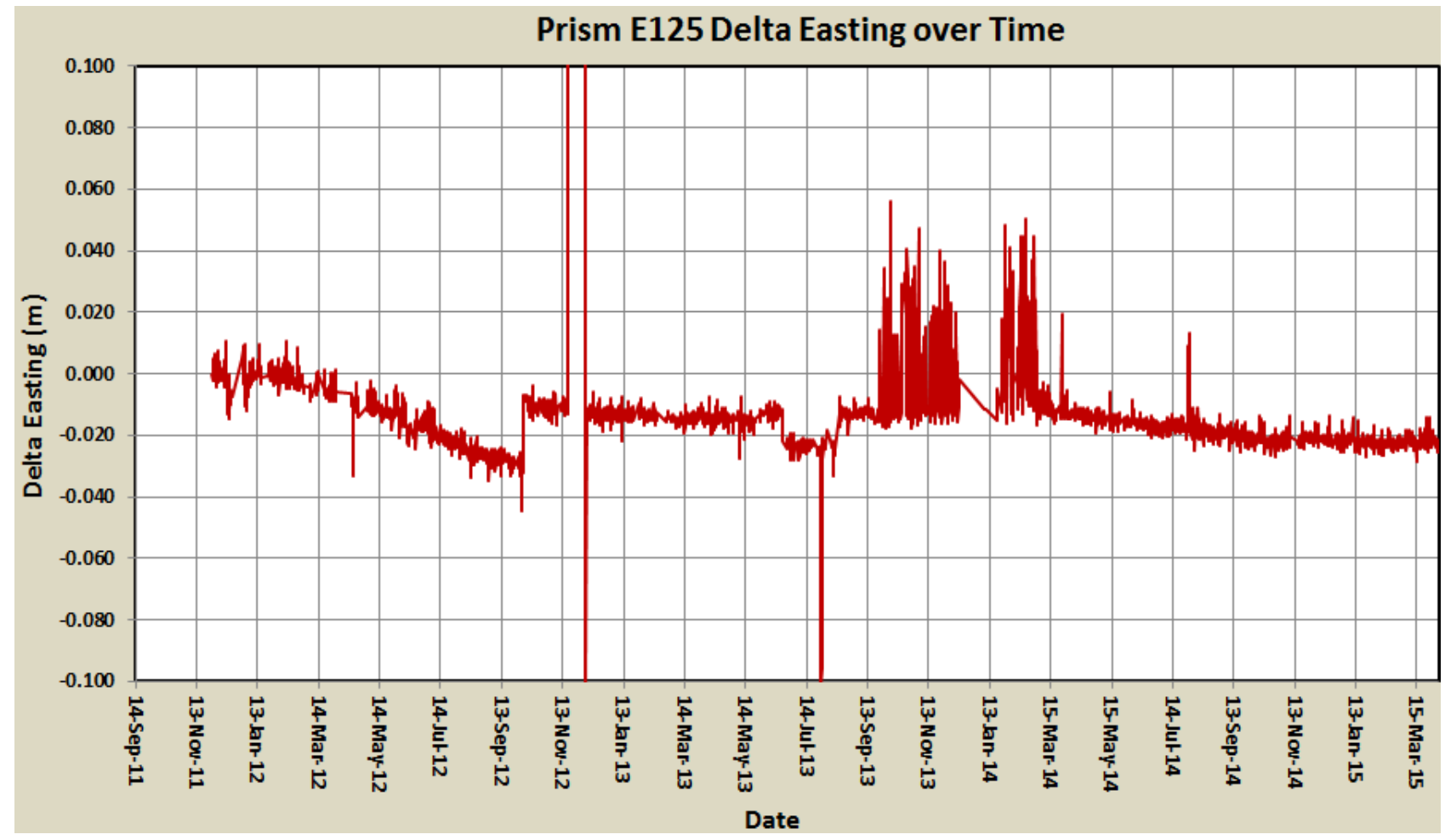

Figure 4 Example of raw prism data graph 


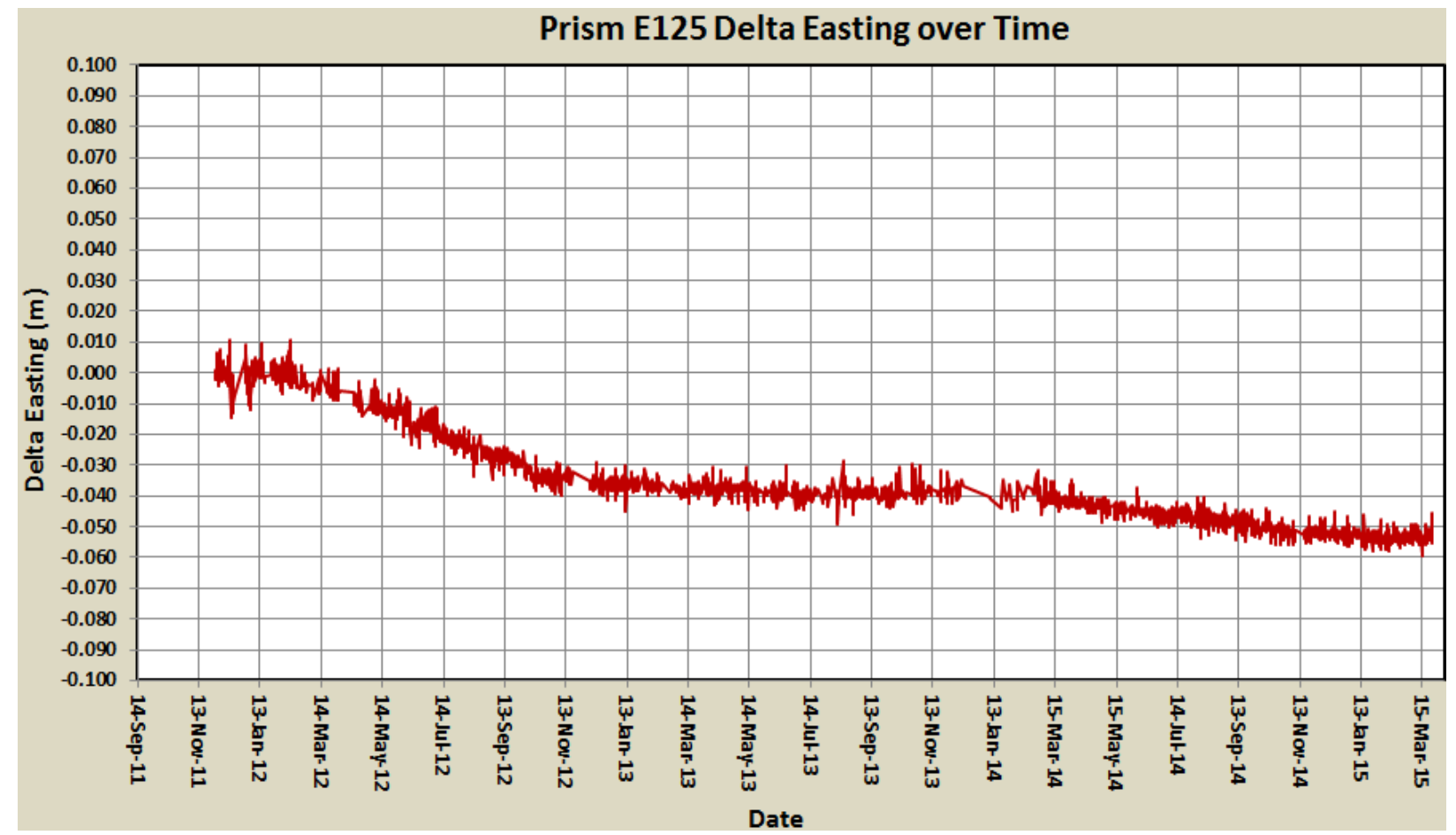

Figure 5 Example of adjusted prism data graph

The non-random outliers on the right side of the above graph were the result of the installation of a prism almost directly in the line of sight of the back sight prism, so the system chose the incorrect backsight on numerous occasions.

The adjusted prism data for delta easting, delta northing and delta elevation were used to calculate the total movement in three dimensions for each prism. This total movement data was then graphed, after which a visual 'best fit' line was created through the graphed data, as shown in Figure 6.

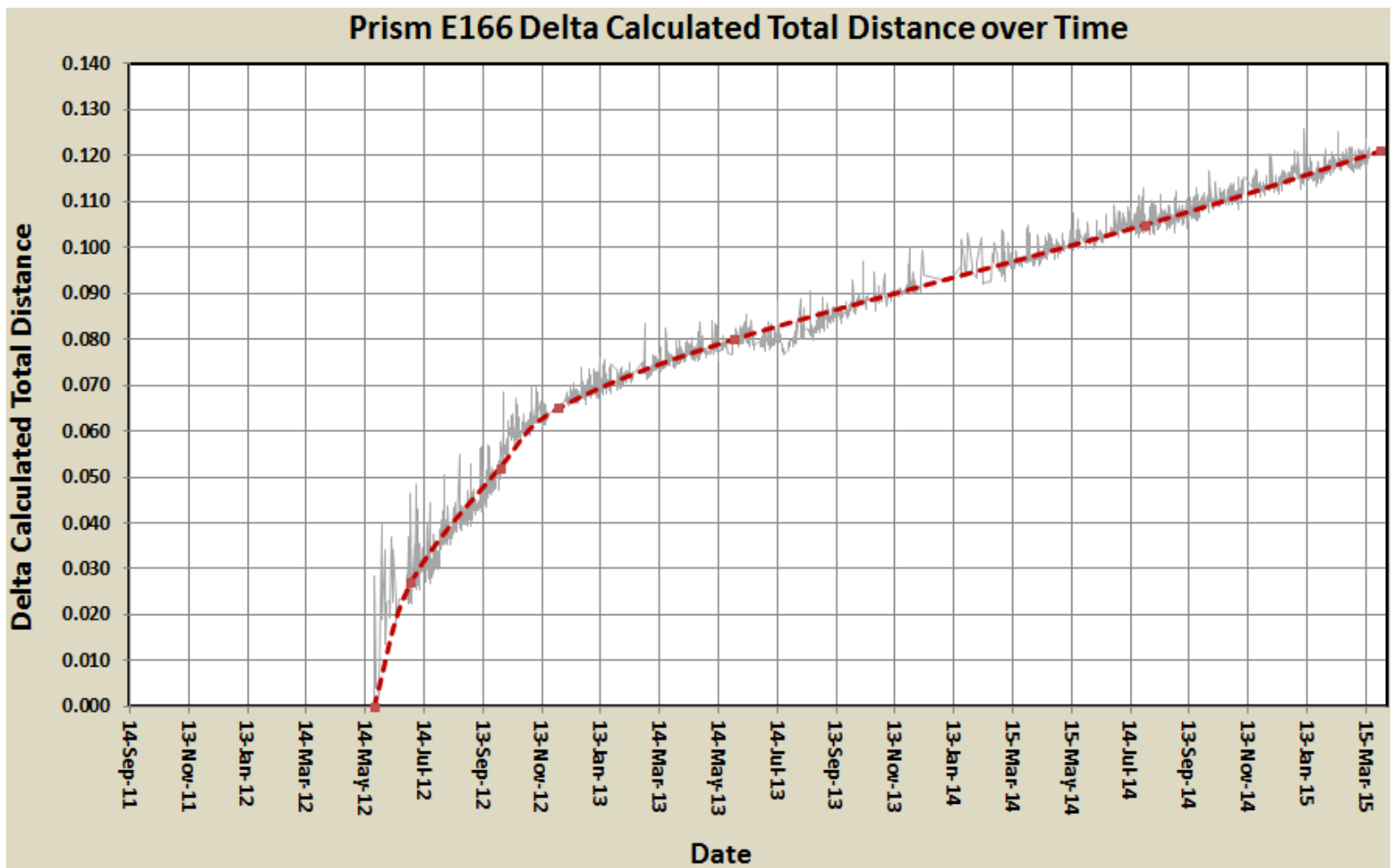

Figure 6 Example of a visual 'best fit' line 
This line, which presented the prism movement without the 'noise' is what was used in the presentations that follow. The process is time consuming and tedious, but it is a necessary process if a potential failure area is to be identified early in the movement cycle.

\section{$5 \quad$ Mining of the intermediate pit phases}

From 2008 through 2011, several phased cuts were successfully excavated without further large-scale instabilities. By December 2011, Stage F had been excavated to the final design limit in the western half of the pit, to the $1047 \mathrm{RL}$ (Figure 7). Note that the original ground surface level varied from 1205 to $1210 \mathrm{RL}$. The Stage E excavation had just been initiated to the final design limit in the eastern half of the pit.



Figure 7 December 2011 pit with prism coverage

By December 2012, the excavation through the lacustrine sediments and saprolites in the eastern half of the pit was almost complete (Figure 8). Stage F had been excavated to the $984 \mathrm{RL}$, and the Stage $\mathrm{E}$ had been excavated to the 1110 RL. Stage G excavation had begun, with the removal of the upper benches of the temporary Stage E haul ramp on the south pit slope. 


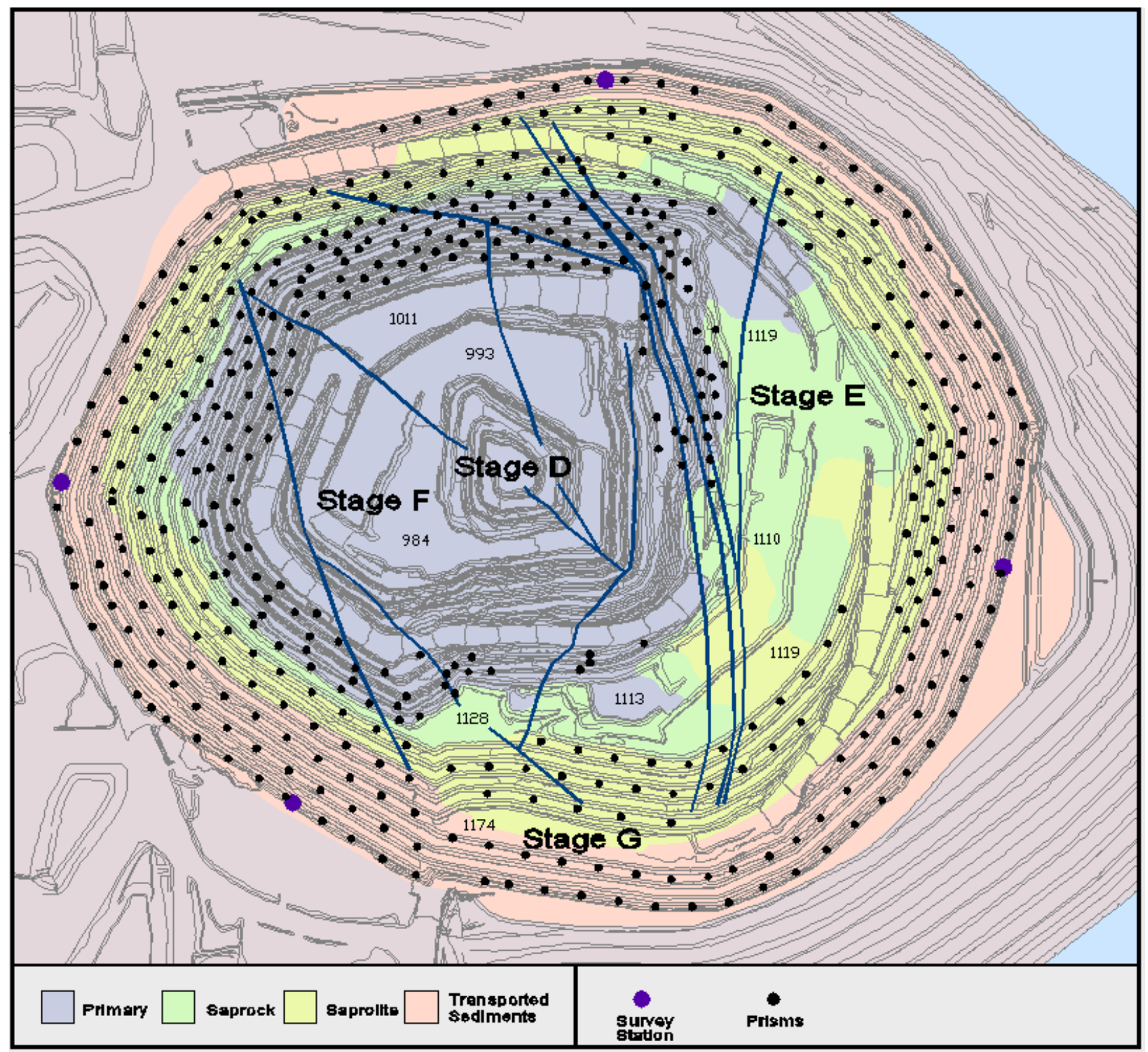

Figure 8 December 2012 pit with prism coverage

With the exception of several bench-scale failures at the base of the lacustrine sediments, the catch berms in the surficial materials performed very well.

\section{Prism creep in southeast slope surficial materials}

In February 2013, a tension crack was observed sub-parallel to the southeast pit crest (Figure 9). It was $20 \mathrm{~mm}$ wide at its widest, but nothing more than a hair line in most areas. Twelve pin sets were placed across it, which were measured weekly to determine if the crack was still active. The pin sets did not show any sign of additional movement after the initial discovery of the crack. 


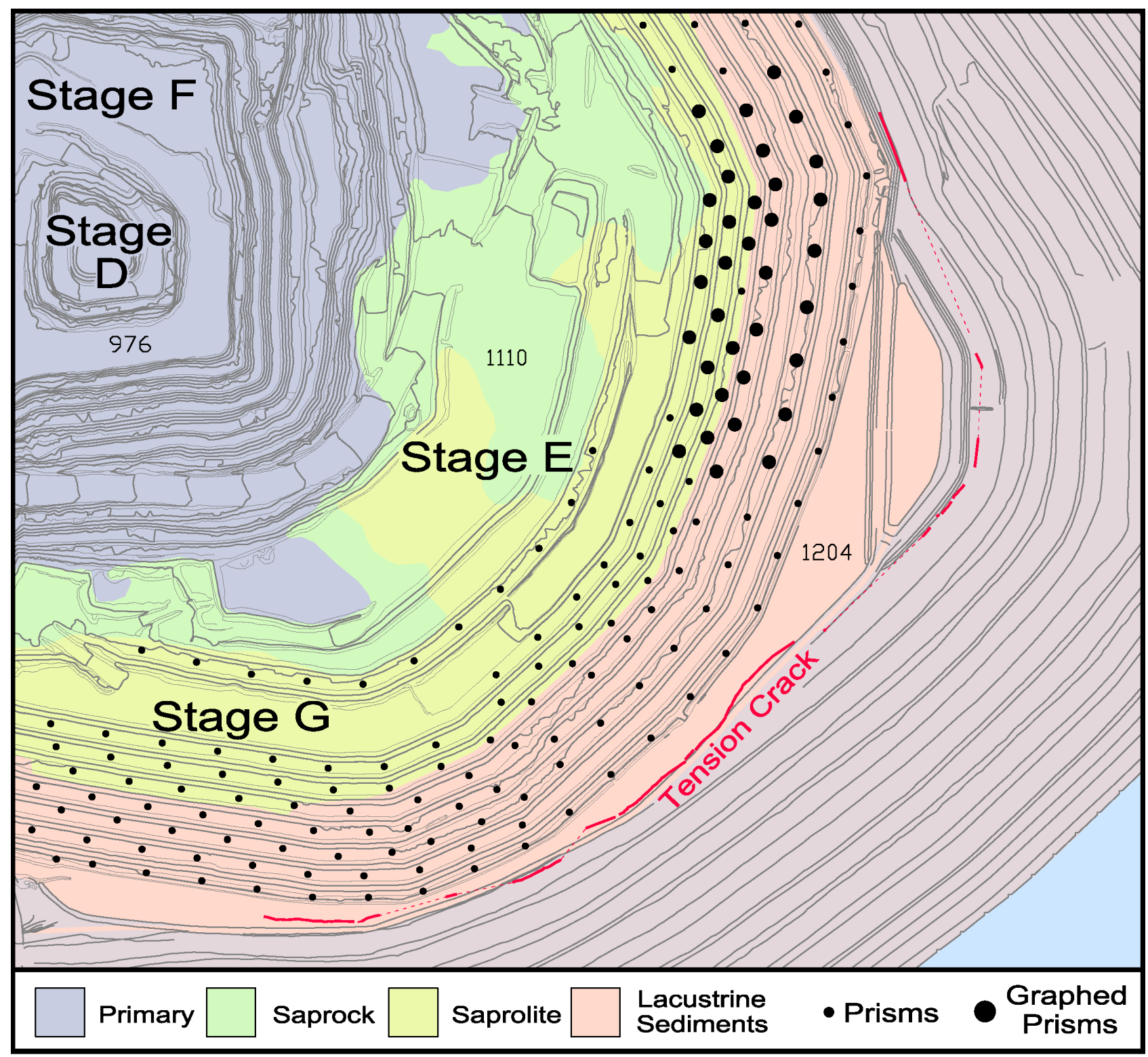

Figure 9 Southeast pit monitoring — February 2013

At that time, movement graphs for prisms located in the saprolite in the southeast pit wall indicated pitward creep of the order of several centimetres. A vector analysis confirmed that the movement was almost entirely horizontal, with a very small upward component indicated on a few of the prisms. The prisms located in the surficial materials in the east pit slope showed higher total movement and higher rates of creep than the prisms located in the southeast or south pit slopes. This difference may have been influenced to some extent by the in situ stresses. Regional stress data suggests that the orientation of the major principal stress is approximately WNW-ESE in the Cowal region (Lee et al. 2010). Higher horizontal stresses in the east-west direction compared to the north-south direction may have influenced the higher movement magnitudes and rates that have been observed on the east wall. This hypothesis is not proven, and it is possible that the regional horizontal stresses only affect the basement rocks and not the surficial materials.

Movement graphs for prisms represented by the larger black dots in Figure 9 are presented together in Figure 10. The orange lines indicate prisms located above the base of the lacustrine sediments, the red lines indicate prisms located in the base of the sediments and the green lines indicate prisms located in saprolite. The stepped dashed black line represents the elevation of the benches on the east side of the pit as Stage $E$ excavation progressed. 


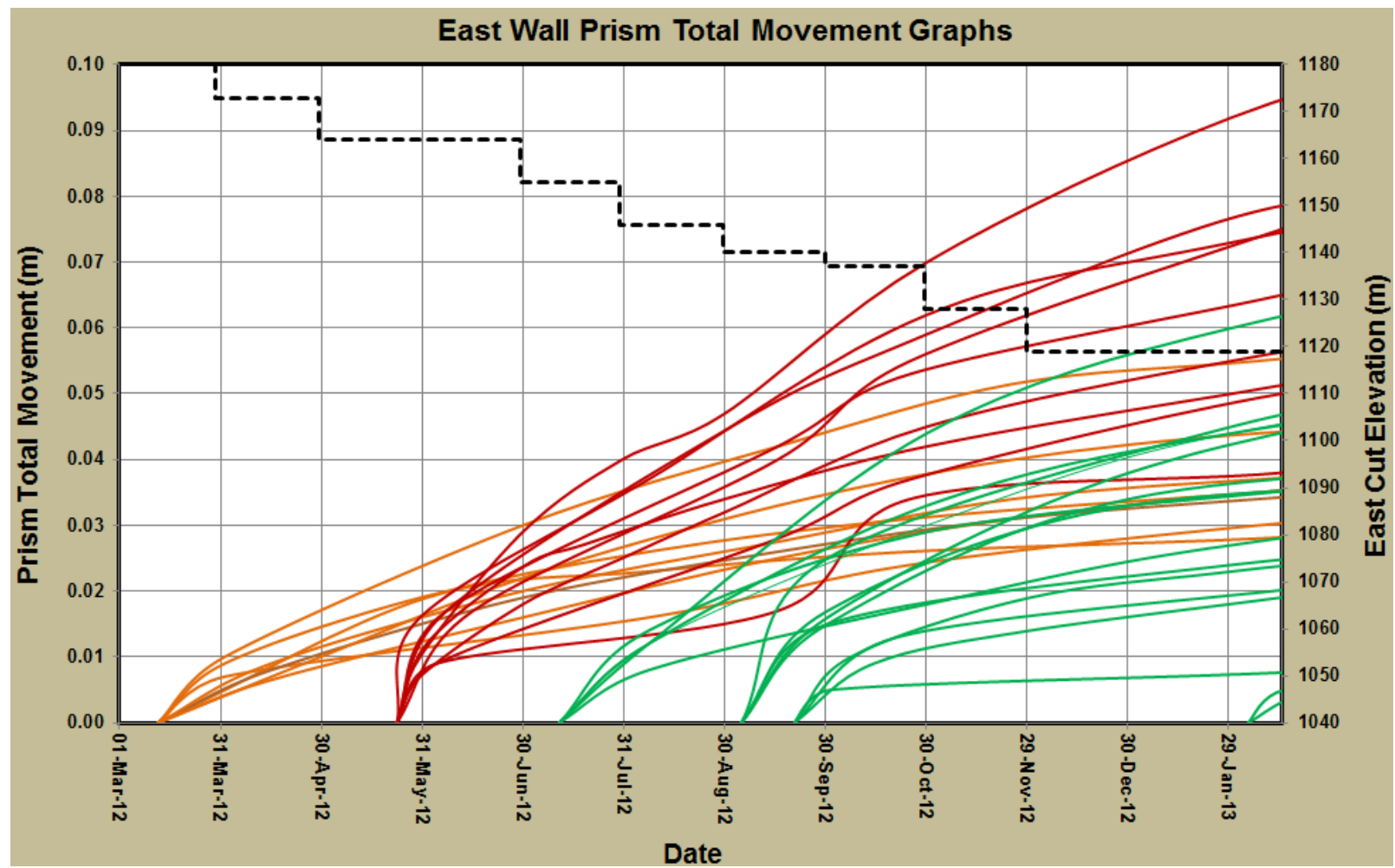

Figure 10 Graph of east wall prism movement as of 15 February 2013

The graphs indicated that the prisms located above the base of the lacustrine sediments had approximately the same rate of creep as the prisms in the saprolite. They also indicated that the creep was gradually slowing down over time. The prisms located in the base of the sediments showed a similar trend, but with more total movement due to the presence of excess water in the sediments there. A maximum movement of $85 \mathrm{~mm}$ was recorded. By September 2013 the excavation through the lacustrine sediments and saprolites on the eastern half of the pit was complete, as shown in Figure 11.

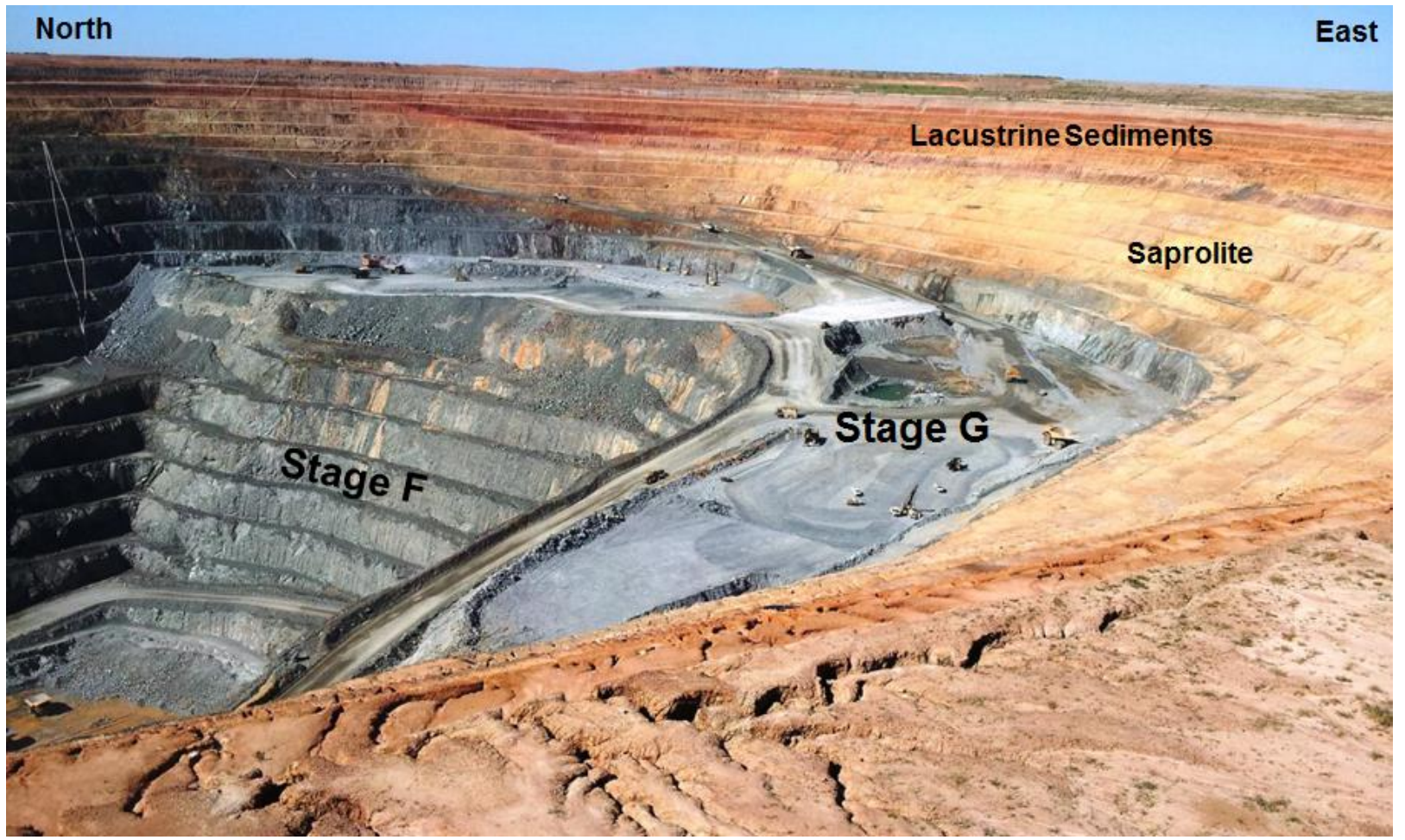

Figure 11 Stage G after successful excavation through the saprolites — September 2013 
The pit walls in the surficial materials continued to remain stable; however, the prism creep continued. Movement graphs (Figure 12) for the same prisms shown in Figure 10, but a year later, indicated a steady rate of creep for many of the graphed prisms. The maximum movement had increased to $135 \mathrm{~mm}$.

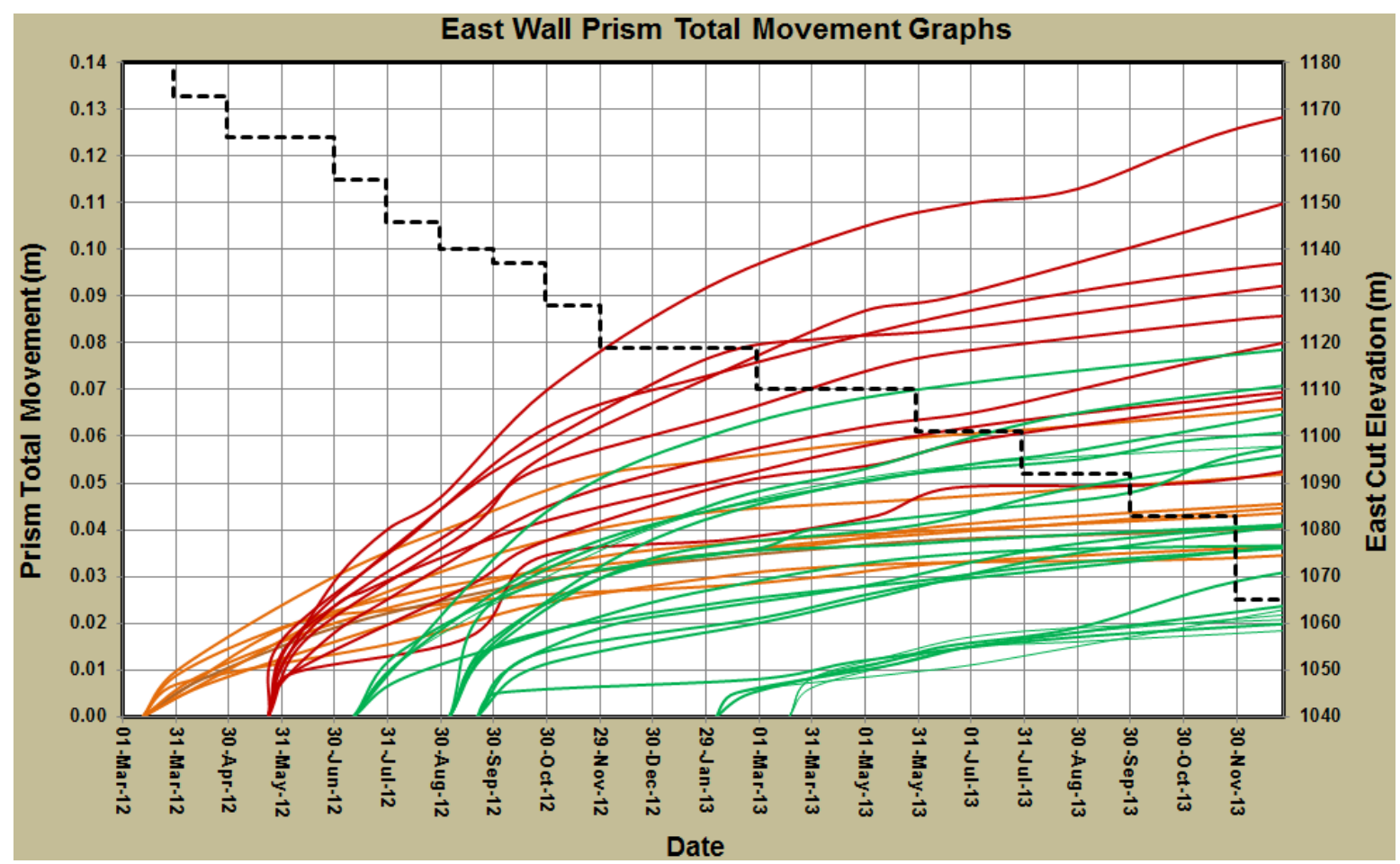

Figure 12 Graph of east wall prism movement as of 15 February 2014

At the time, it was hoped that the observed prism creep was the result of elastic deformation of the pit slopes due to mining and not indicative of the onset of failure. Due to the elevated water content at the base of the lacustrine sediments, the prisms located there were expected to continue to creep until multi-bench failures occurred (Figure 13), as had been observed in several areas in the southeast pit slope. These multi-bench failures were a nuisance, but were unimportant in terms of the stability of the overall pit slope.

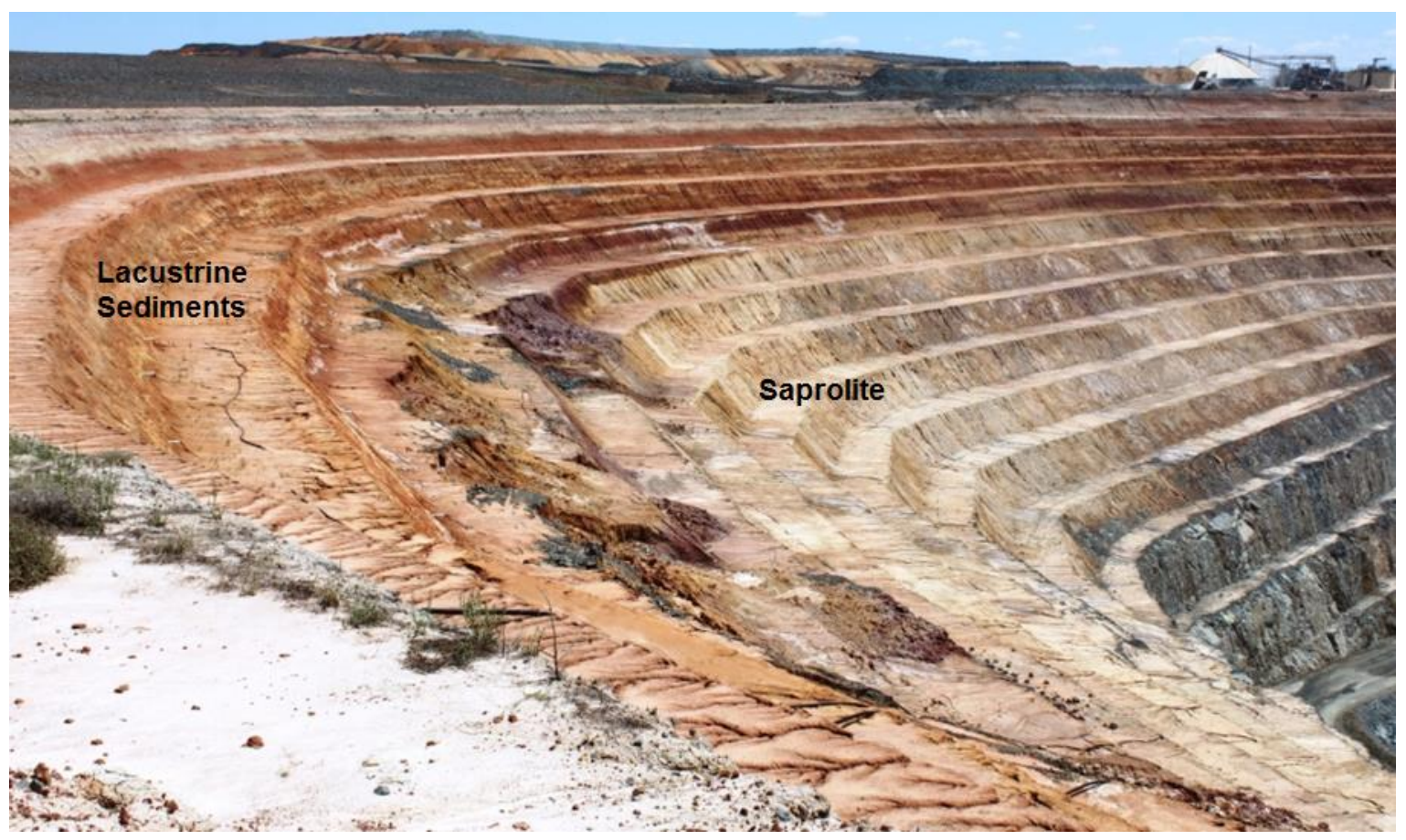

Figure 13 Multi-bench failure at the base of the lacustrine sediments 


\section{$7 \quad$ Prism movement in the overall pit slopes}

Documentation of the prism movement in the primary rock has also been performed, allowing a comparison of monitored displacements in the primary and surficial materials. By March 2015, the Stage $G$ east wall had been excavated into the Cowal Fault Zone in the primary rock (Figure 14).

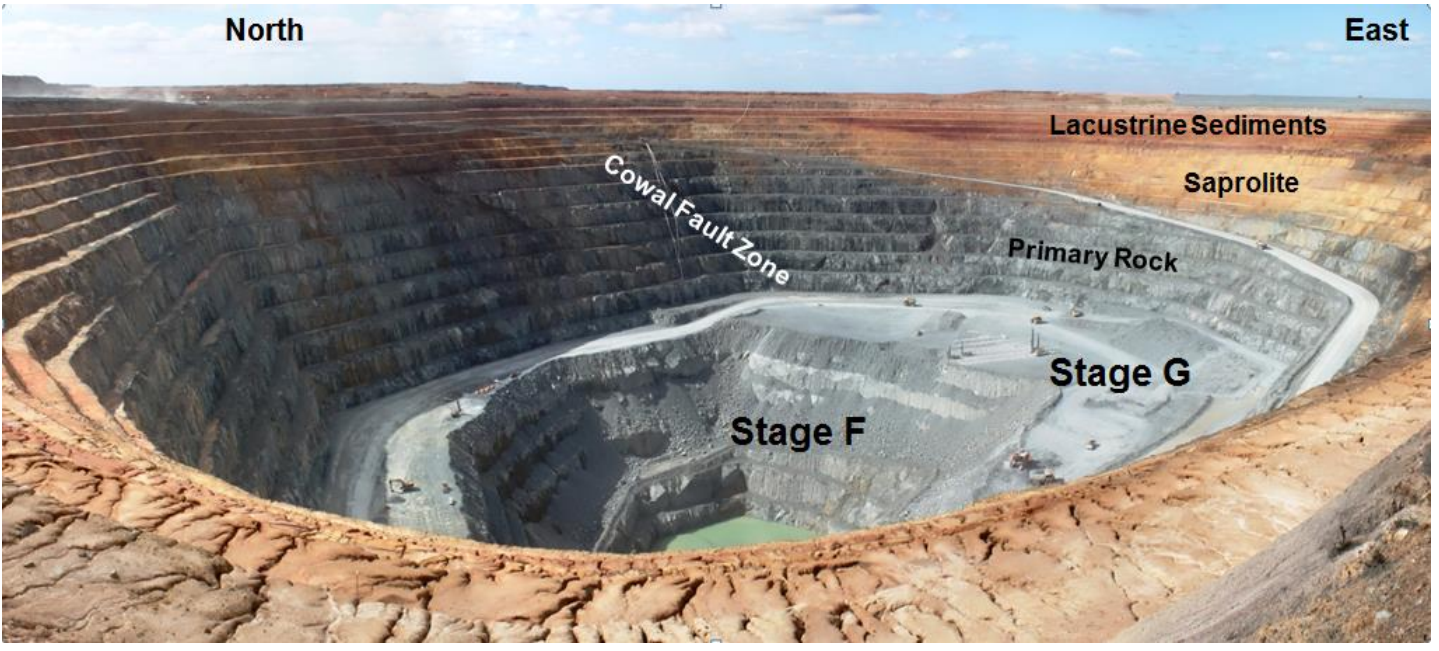

Figure 14 Pit as of 15 March 2015

Prism data was processed for a series of cross-sections around the entire pit perimeter, as shown in Figure 15.

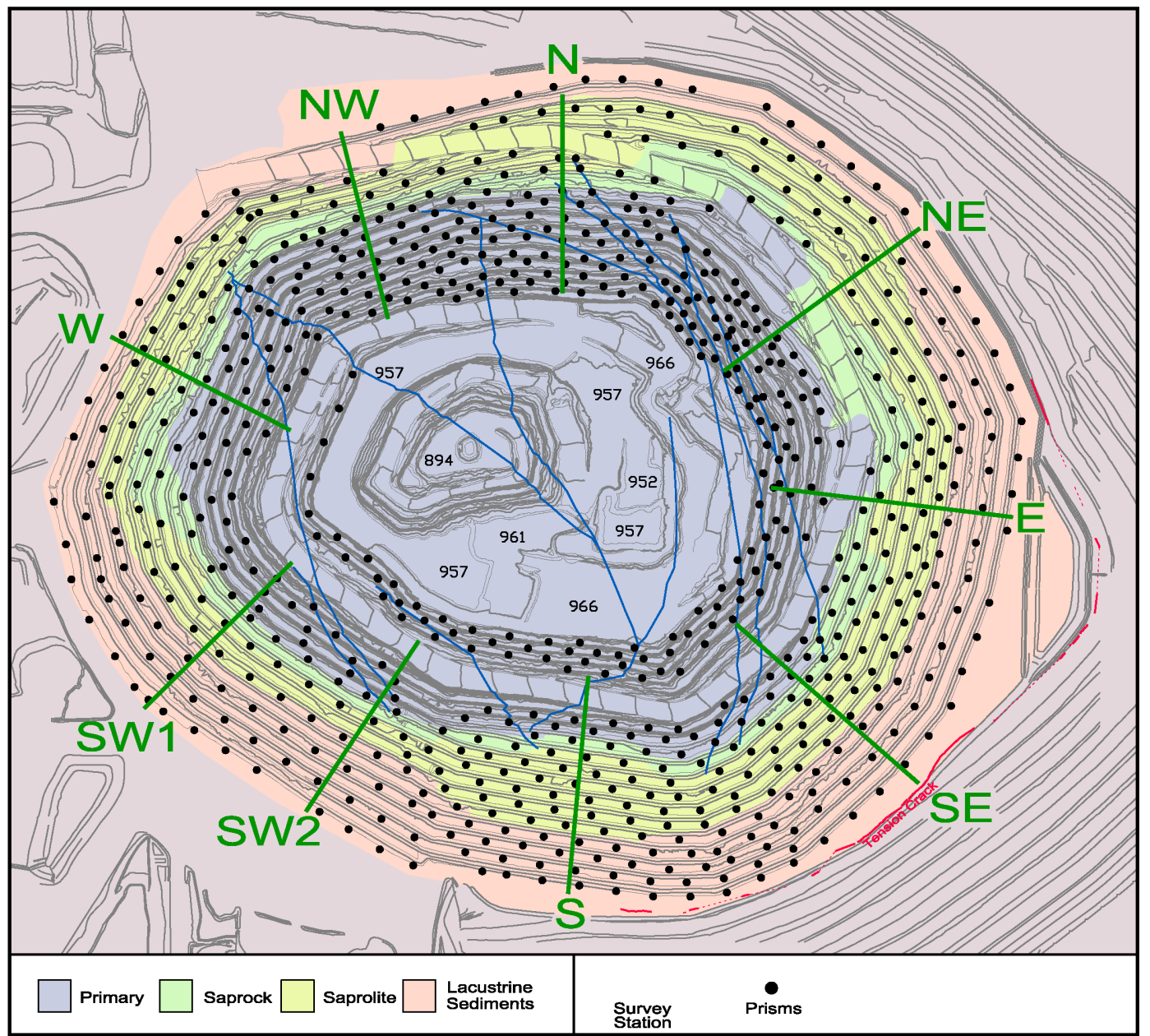

Figure 15 September 2015 pit with prism section lines 
Prism movement graphs for the cross-sections were created by plotting the elevation of each prism over time, minus the total prism movement multiplied by a factor, as shown in the formula below:

$$
\text { Prism Elev = Elev Initial }-(500 * \Delta \text { Movement })
$$

The initial elevation was the first surveyed elevation of the prism, whilst the delta movement was the total movement from the initial position. The purpose of the factor (500) was to magnify the movement so it would be displayable on Excel graphs. Prisms were colour-coded by rock type, as follows:

- Lacustrine sediment prisms have orange lines.

- Saprolite prisms have light green lines.

- Saprock prisms have dark green lines.

- Primary rock prisms have purple lines.

- Cowal Fault Zone prisms have red lines.

Excavation progress for the final cut is shown on the movement graphs as stepped black lines. It must be remembered that these graphs are not cross-sections; they are graphs of relative movement over time. For comparison purposes, all graphs have the same beginning and end dates, as well as the same upper and lower elevation limits.

The prisms on Section $\mathrm{N}$ have remarkably similar movement lines (Figure 16). They all have the same delayed reaction to the mining stoppage in September 2012, indicated by the dashed red line on the graph. No material was excavated from the final wall for about two years, so the movement graphs are relatively flat. The graphs show a similar delayed reaction to the resumption of mining in September 2014.

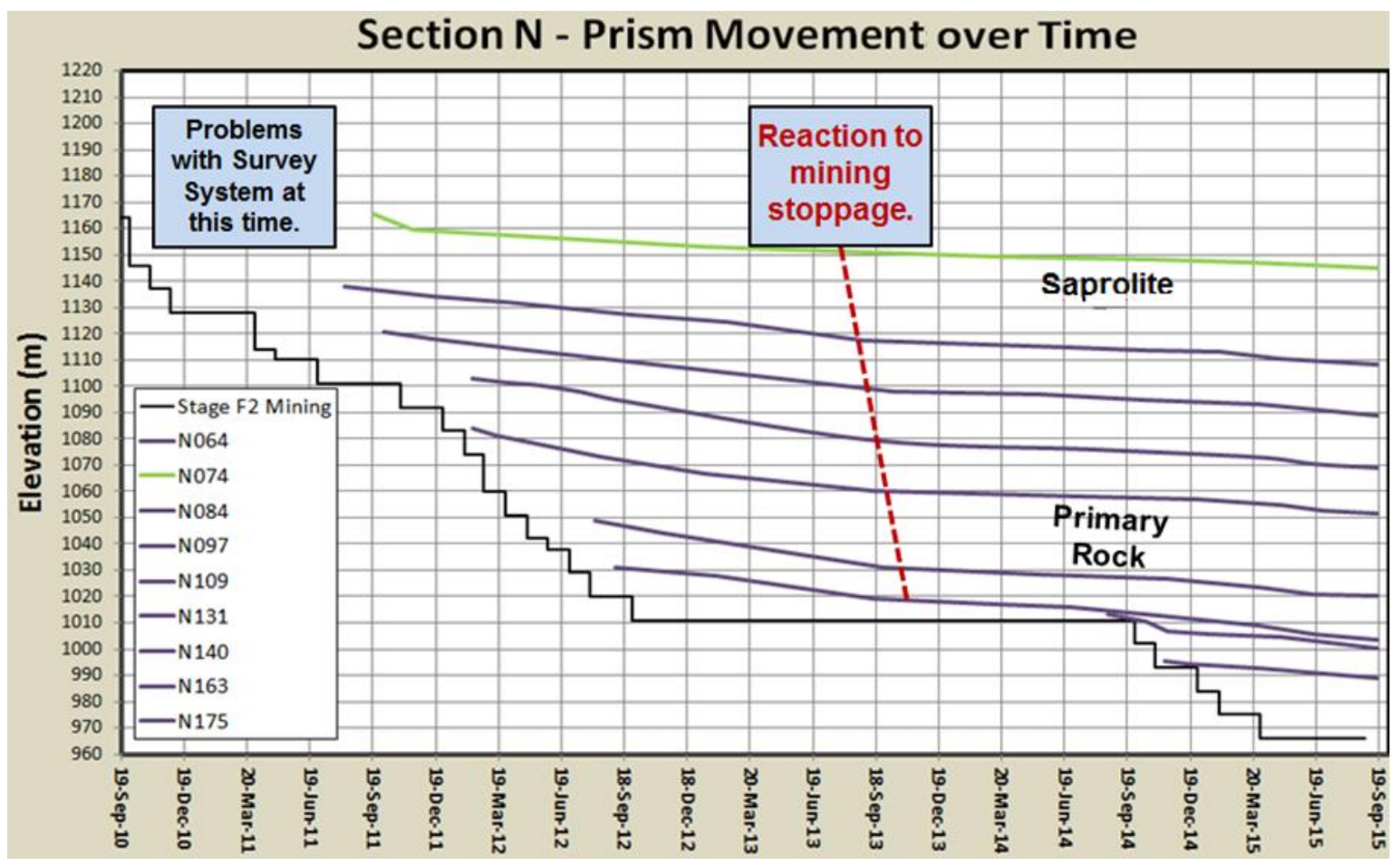

Figure 16 Prism movement on pseudo section $\mathrm{N}$

The prisms on Section NE also have remarkably similar movement lines (Figure 17). There is a remarkable similarity of the prism movement in the lacustrine sediments and saprolite with the prism movement in the primary rock below. Note that two prisms had high initial movements, but each settled into the same overall pattern after a few months. The prisms in the Cowal Fault Zone showed a higher initial movement rate than the prisms in the primary rock above, which was a source of concern. However, after about nine months, these prisms also settled into the same overall movement pattern. 


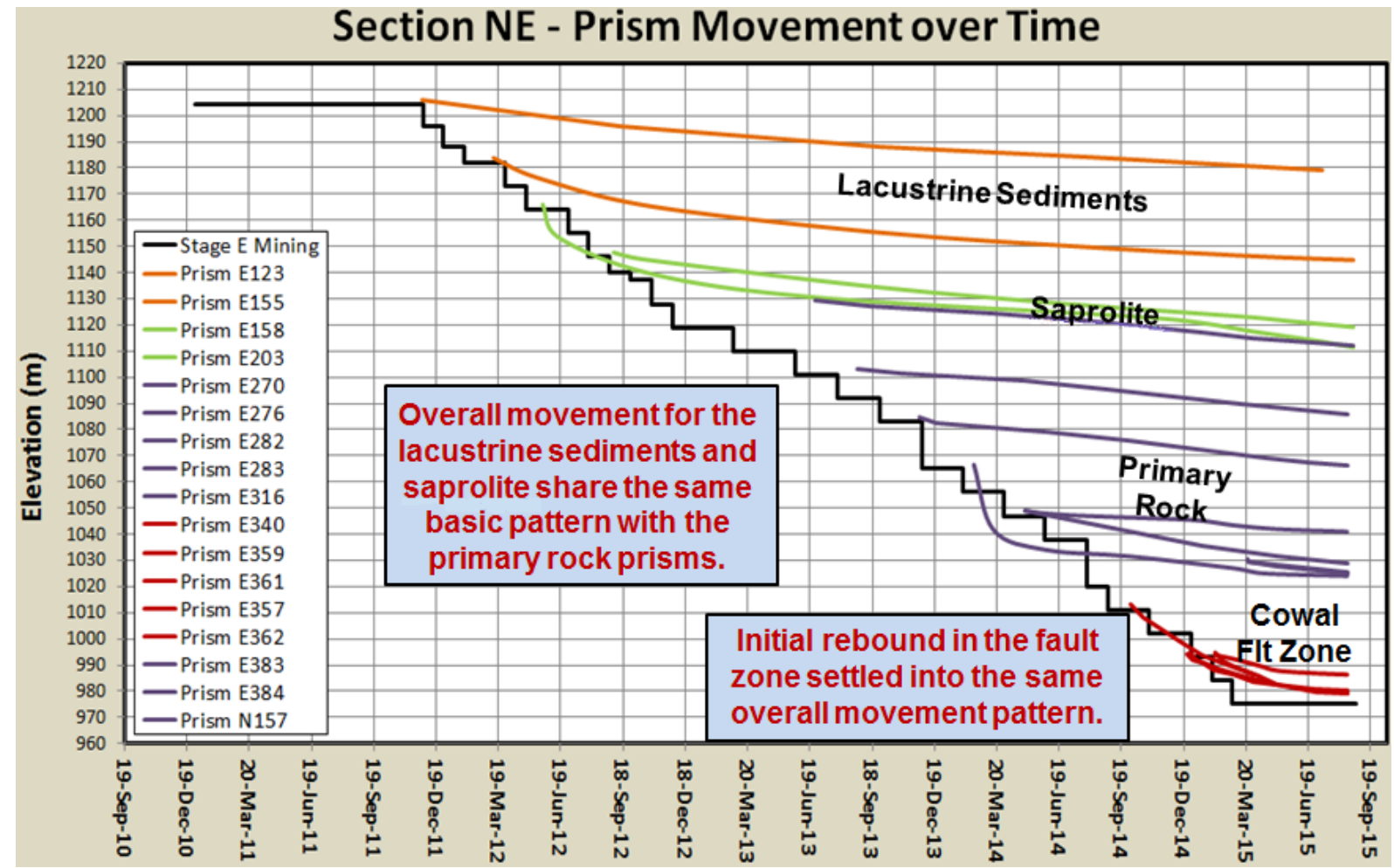

Figure 17 Prism movement on pseudo section NE

The prisms on Section E (Figure 18) showed a similar trend, gradually becoming sub-parallel regardless of the rock type, although the movement rates for this cross-section are higher than those on the other cross-sections. The sub-parallel movement pattern for the entire cross-section was not expected when the study was begun, due to the large differences in material properties between the lacustrine sediments and saprolite versus the primary rock.

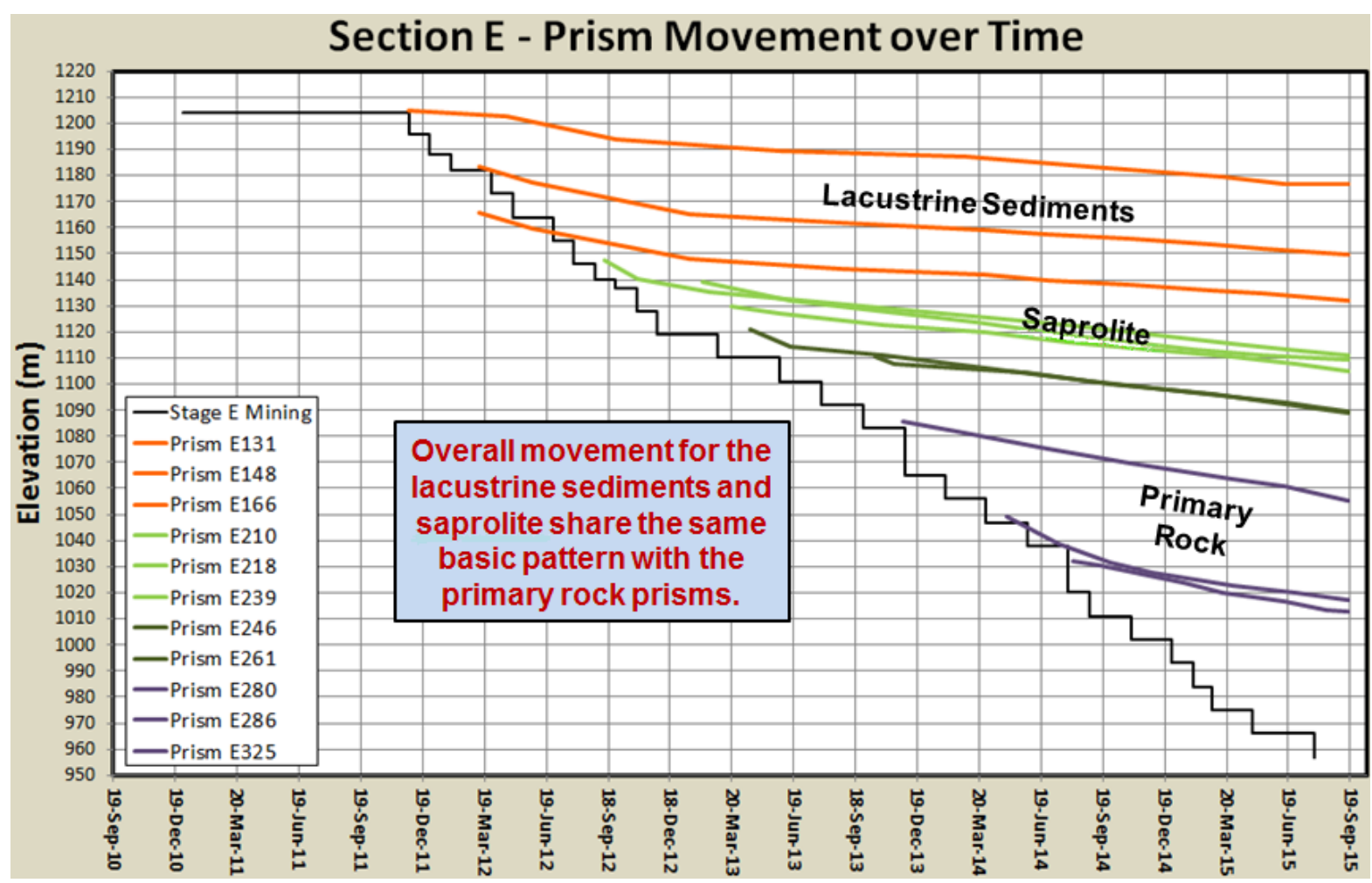

Figure 18 Prism movement on pseudo section $\mathrm{E}$ 
The prisms on Section SE (Figure 19) show the same trend as in the other cross-sections, except that there is one prism, indicated by the dashed line, which was lost in a bench-scale failure at the base of the lacustrine sediments. Note that the prism was moving at the same rate as the nearby prisms at the time it was lost.

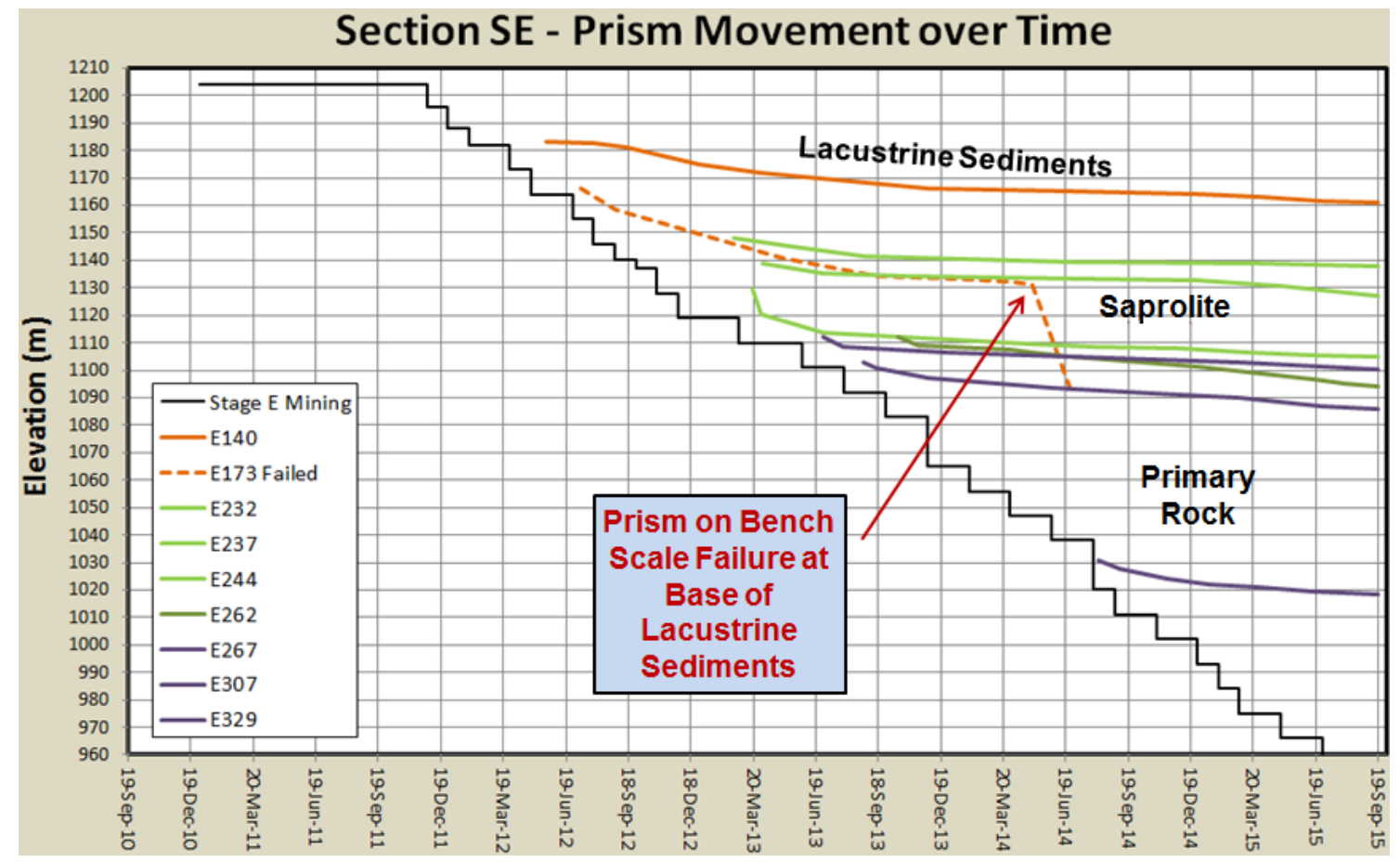

Figure 19 Prism movement on pseudo section SE

The prisms on Section S (Figure 20) show the least movement of all. The section was located where a temporary ramp was mined out in the last phase of the Stage G cut. A lot of the pitward movement had probably occurred before the temporary ramp was mined out, which would explain the low apparent movement of pit slope in that area.

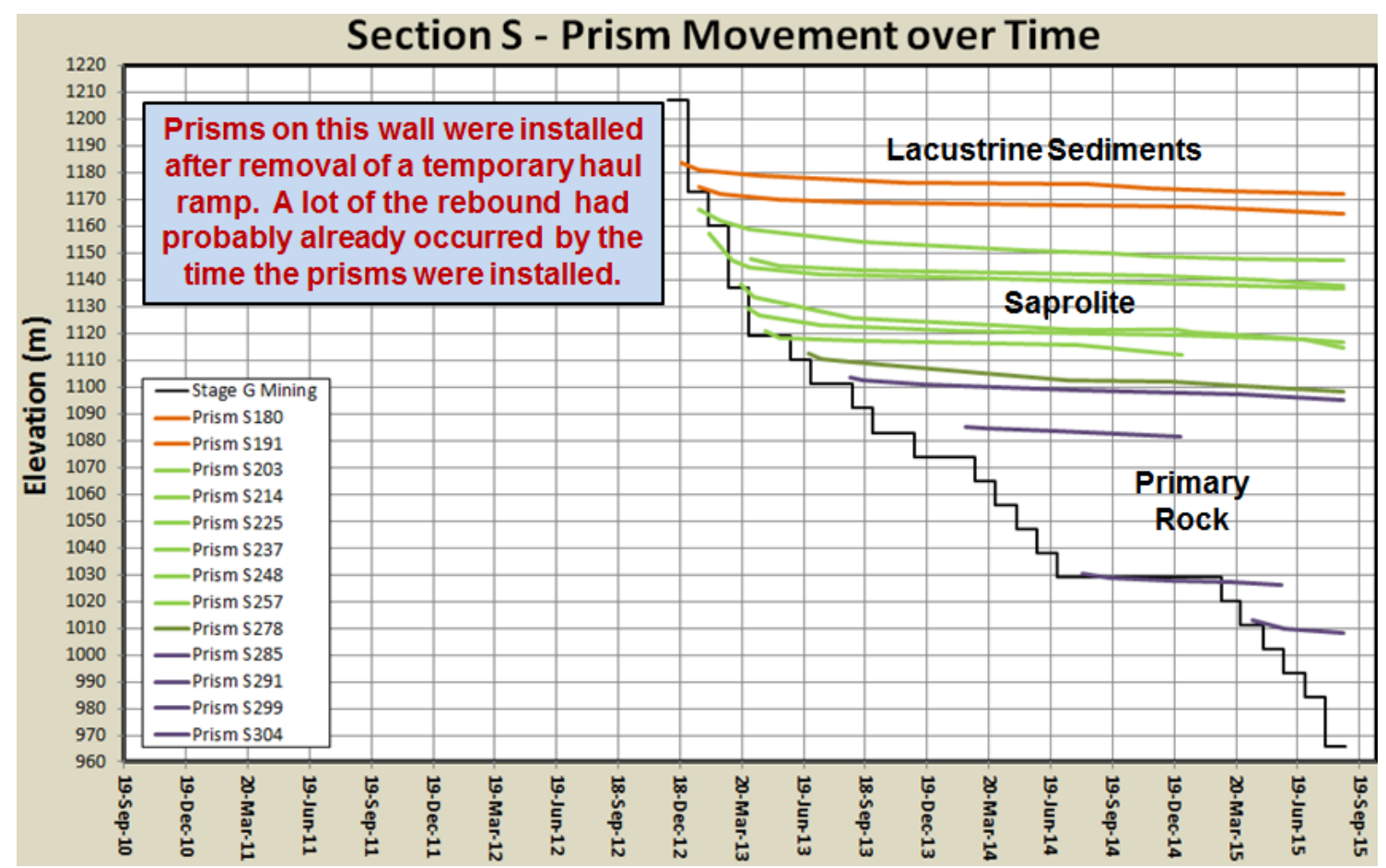

Figure 20 Prism movement on pseudo section $\mathrm{S}$ 
There were problems with the automated monitoring system prior to 1 October 2011, so it was not possible to plot prism movement data before that date. The apparent flatness in the following cross-sections, which were mined to primary rock prior to that date, can be explained by the lack of early monitoring data on these sections. The prisms on Section SW1 (Figure 21) show an absence of apparent movement, due in part to stoppage of mining of the west pit walls from late 2011 to early 2014, and in part to the lack of monitoring data for the initial mining sequence.

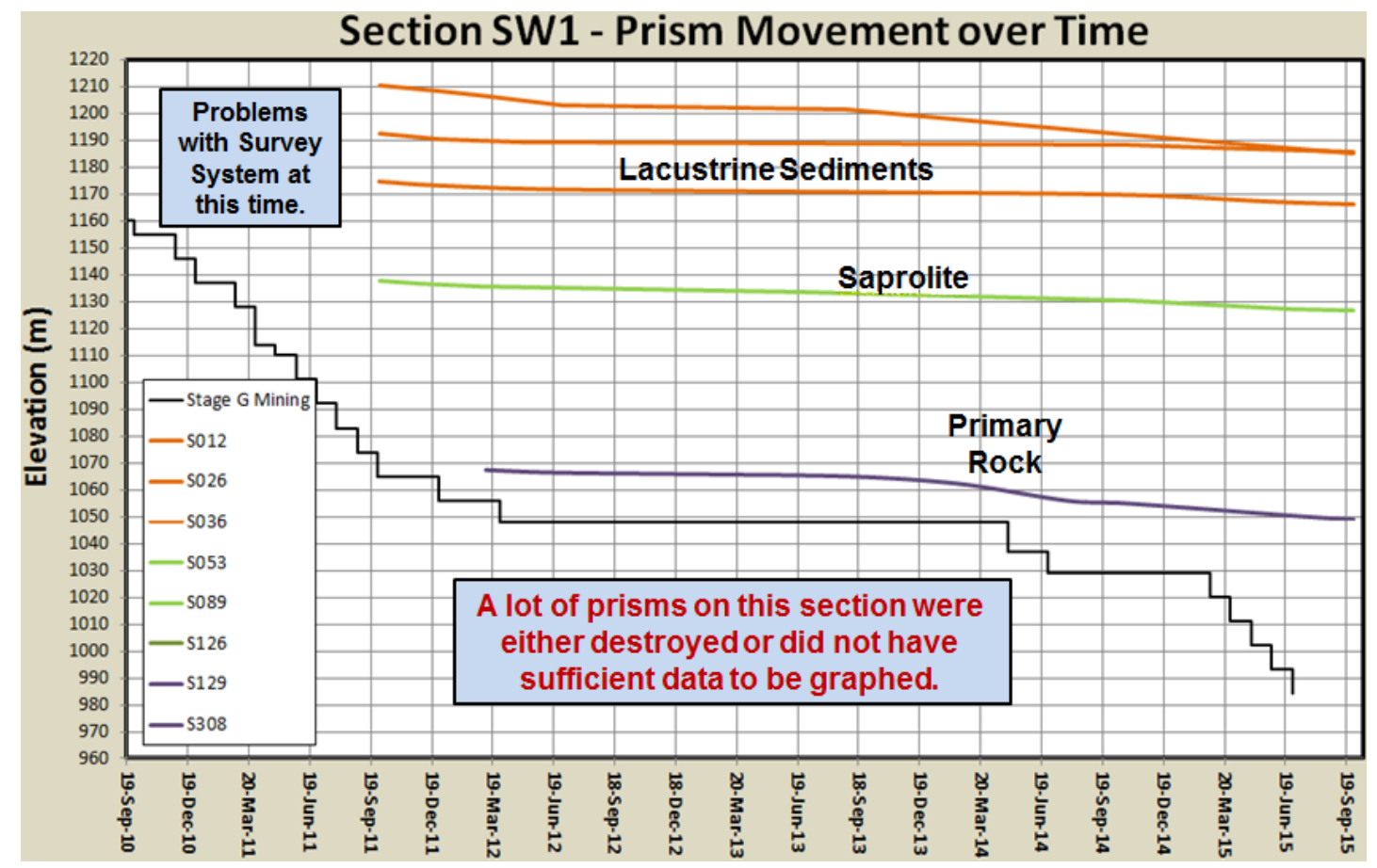

Figure 21 Prism movement on pseudo section SW1

The prisms on Section SW2 (Figure 22) show a delayed response due to mining stoppage, as was observed on Section N.

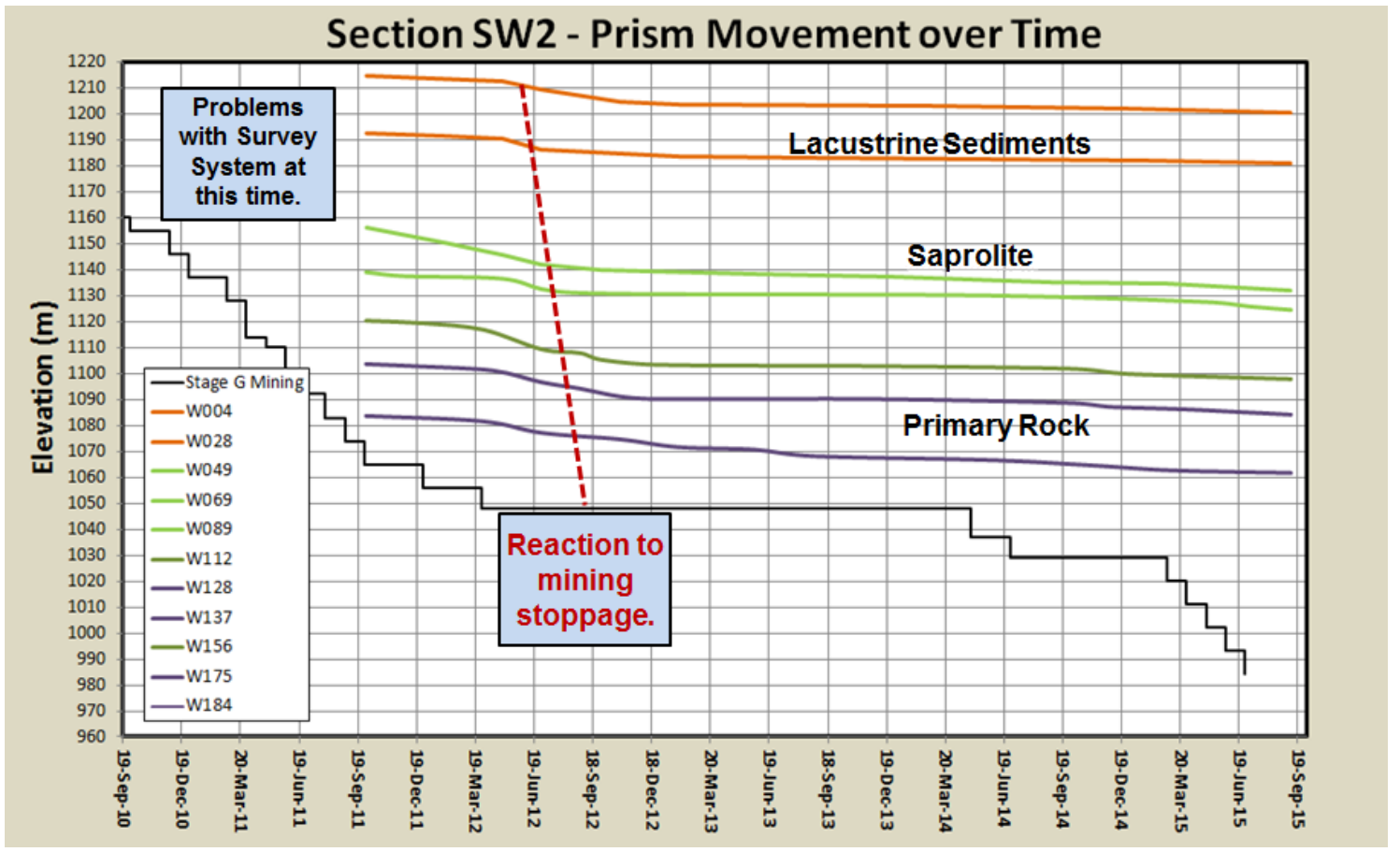

Figure 22 Prism movement on pseudo section SW2 
The prisms on Section W (Figure 23) show a similar delayed response due to mining stoppage, as well as a delayed response to resumption of mining in June 2014.

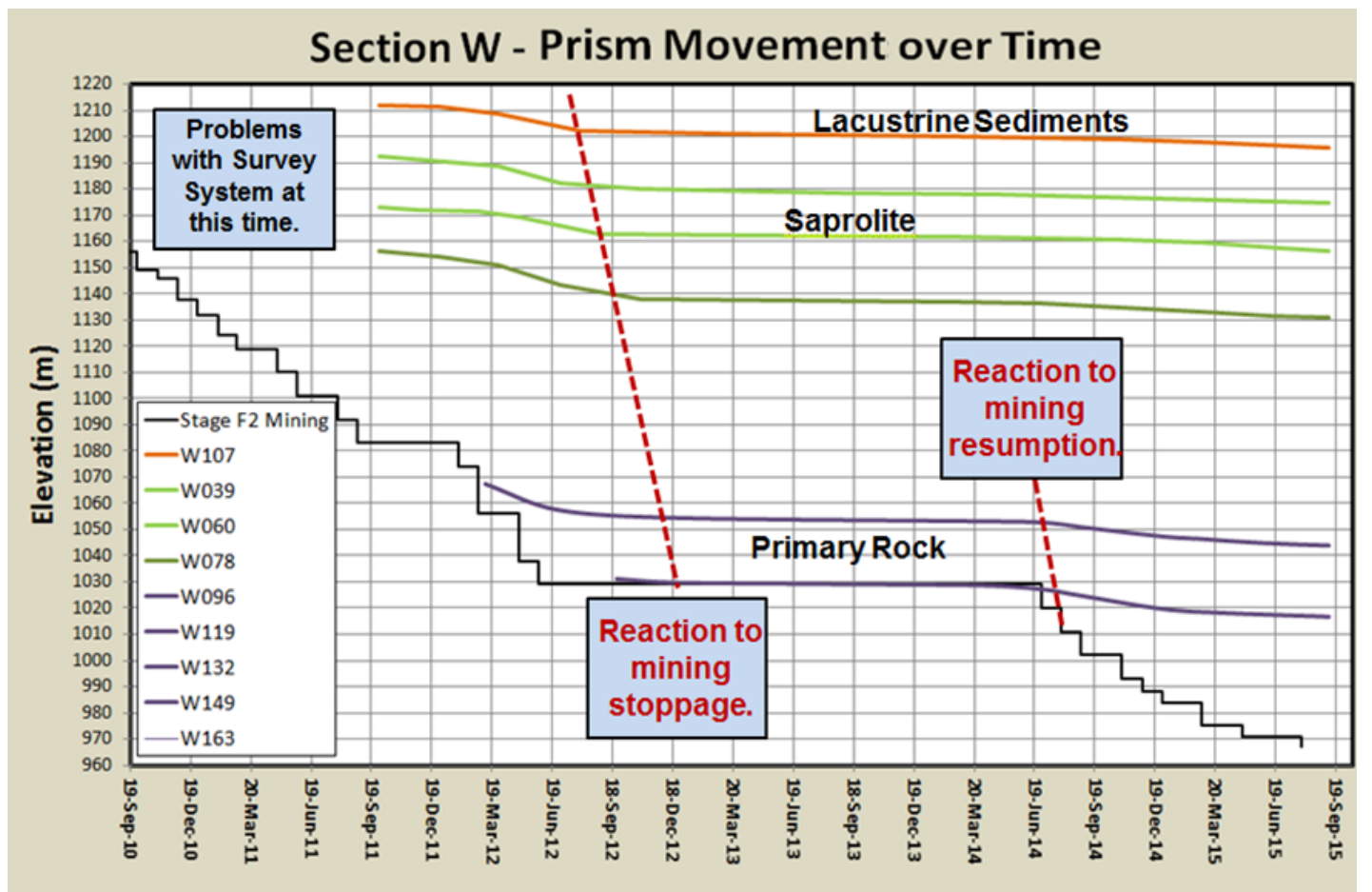

Figure 23 Prism movement on pseudo section W

The prisms on Section NW (Figure 24) show a similar delayed response due to mining stoppage, as well as a large initial prism movement for one prism, which quickly settled to the overall pattern for the section.

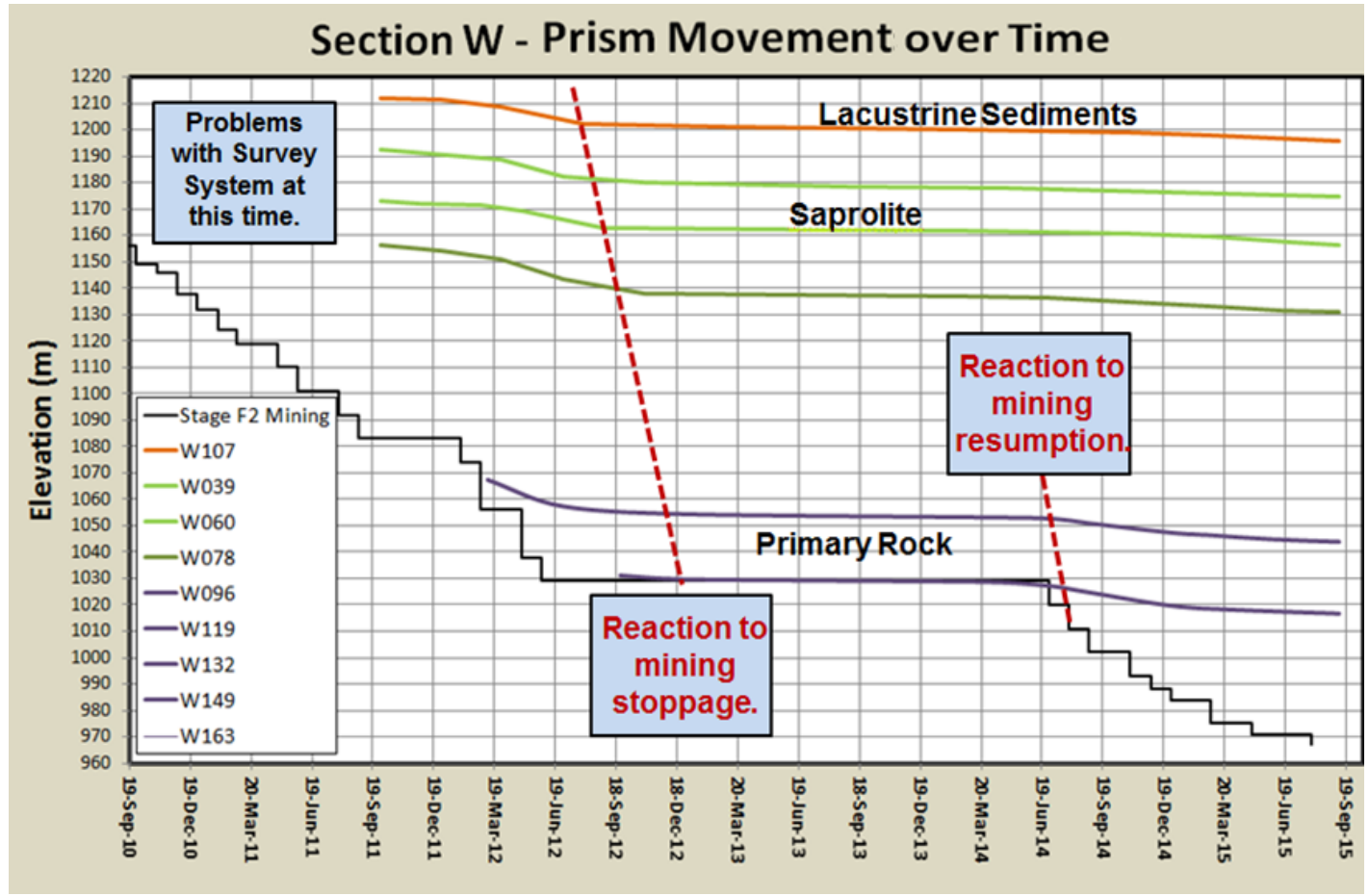

Figure 24 Prism movement on pseudo section NW

Two significant observations for these cross-section plots are: 1) prisms show sub-parallel movement for the entire section, regardless of lithology, and 2) the movement is greatest for the section on the east pit wall. 


\section{Assessment of the monitored pit wall displacements}

Based on the authors' experience, it is not surprising that ongoing displacements are being monitored in the Cowal slopes, particularly as mining continues at the base of the pit. On other projects, the authors have found that slope displacements can continue for a long time after the completion of a pit or a particular cutback. For most pit slope failures, clear acceleration is seen in the monitored displacements prior to failure, as shown in Figure 3. The current monitoring data presented above does not show any clear acceleration in displacement rates.

Sullivan (2007) provides a classification of pit slope movement rates to assist with mine planning. Based on this, the monitored displacements at Cowal generally fall within the 'Low creep' and 'Significant creep' categories, which do not indicate that the slope is likely to fail at some time in the future. For some of the prisms, again based on the Sullivan (2007) classification, the prism rates for certain periods indicate that shear displacement has occurred along structures within the rock mass, which can be expected in any large open pit.

Based on the model proposed by Mercer and Stacey (2008), monitored deformations in the primary materials fall within the 'Stage 1 and/or Stage 2 Pre-Collapse Creep Modes'. This does not indicate whether or not slope instability can be expected.

In May 2015, a numerical analysis was performed using 3DEC (Itasca 2013) to assess the current and future stability of the Cowal slopes. A plan view showing the primary rock domains and faults in the model as of May 2015 is shown in Figure 25.

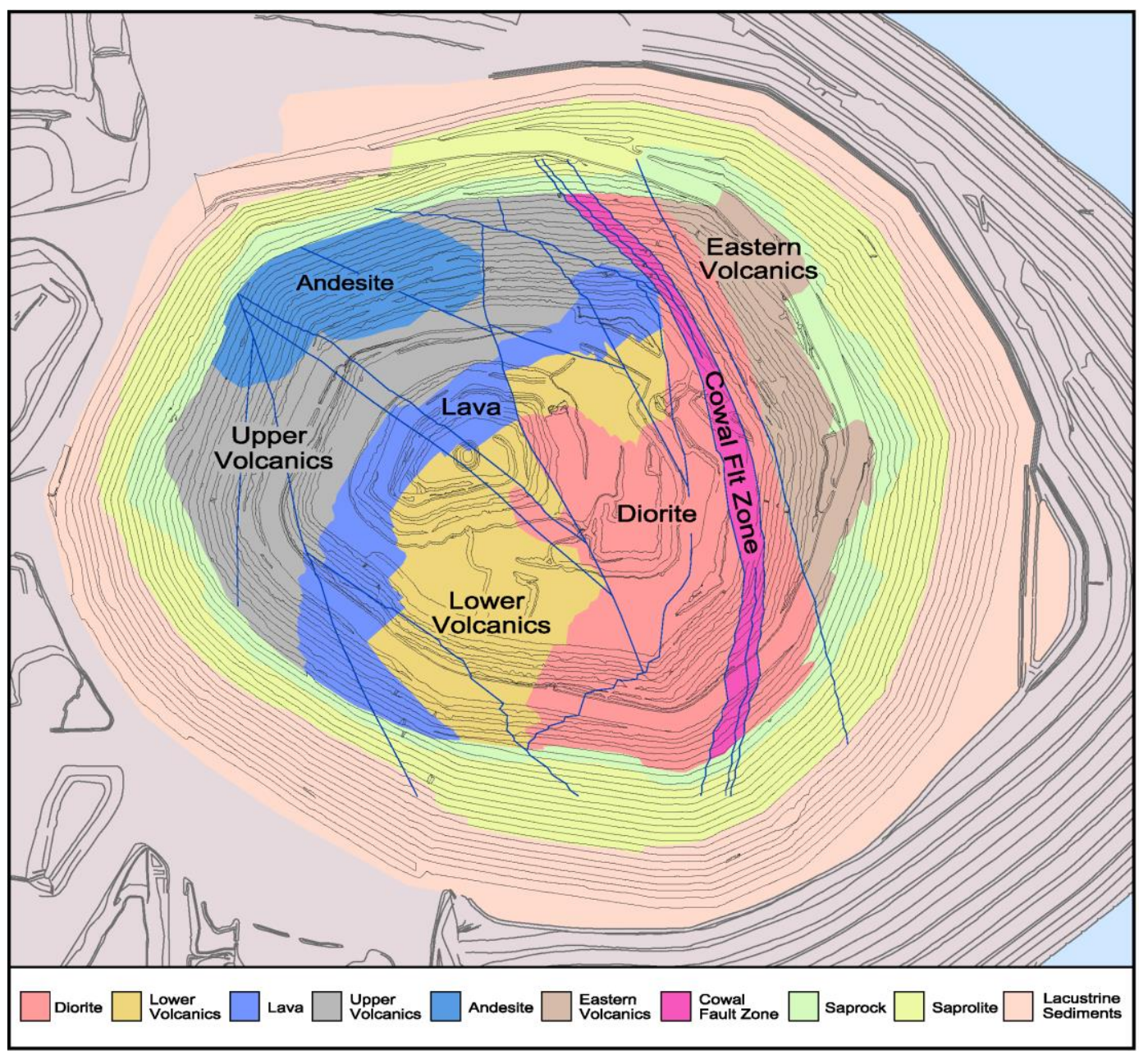

Figure 25 Primary rock numerical model zones 
At the current excavation stage, a reasonable correlation was achieved between the modelled and monitored displacement magnitudes and rates. A chart is provided in Figure 26 showing prism and model displacements since installation for five selected prisms around the existing walls. It is seen that the displacement magnitudes and rates produced by the model correlate well with the actual prism displacement rates. It is noted that the rate produced by the model at the location of prism N168 is significantly higher than the other prisms, which is consistent with the actual prism data. This prism is situated within the relatively low strength and low modulus Cowal Fault Zone.

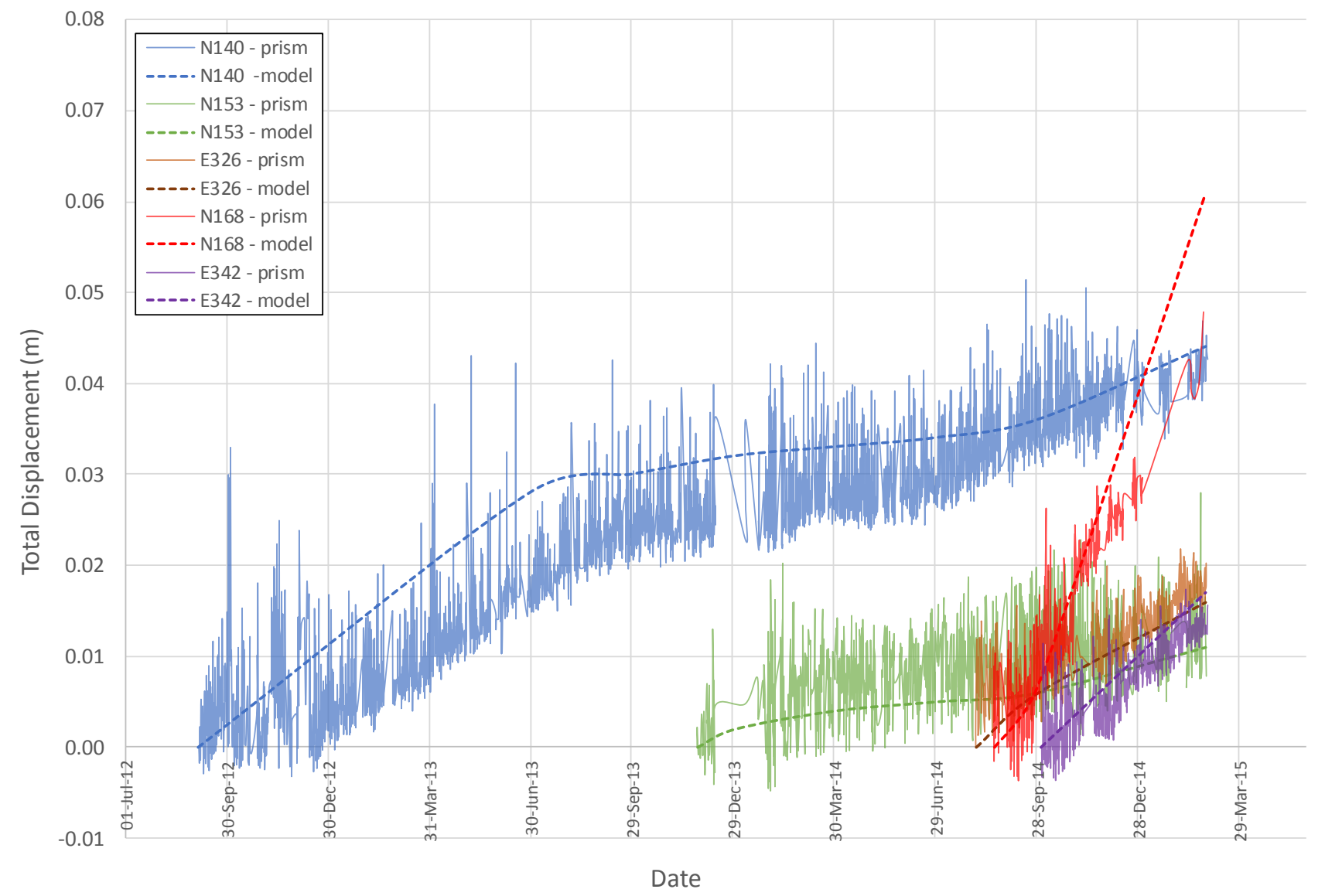

Figure 26 Model versus actual prism displacements

The favourable correlation between modelled and monitored displacements provides confidence that the adopted elastic properties (Young's modulus and Poisson's ratio) are reasonable, but does not necessarily indicate that the adopted strength properties (cohesion, friction angle and tensile strength) are reasonable. Separate back-analyses were also performed for one of the 2007 failures, which, along with the results of laboratory testing, were used to estimate and refine the adopted strength properties for the surficial materials. Therefore, calibration to the existing slope performance and back-analysis of the previous failure provided confidence that both the elastic and strength properties adopted for forward analyses were reasonable.

The analyses for the current pit indicated that the displacements that have occurred to date are predominantly elastic. The model also indicated some shallow plasticity in some areas, particularly in the weaker surficial materials. This modelled plasticity does not indicate slope failure, but does suggest that some plastic strains have occurred in the soils and rock mass in localised areas, which can be expected for any large-scale excavation. It is expected that more visible damage, such as the formation of tension cracks, would be identified if more significant plastic strains were to occur. 


\section{Conclusion}

Several conclusions and/or observations can be made about the observed prism movement at the mine:

- Elastic deformation of pit walls will continue as long as mining continues in the wall below. In many cases, these movements will probably continue for a while after the completion of mining.

- For stable slopes, prism movement for the surficial materials are generally sub-parallel to each other.

- For the surficial materials, total prism movement may not be a good indicator of relative stability, as some prisms show high initial movement rates, but eventually 'settle down' to movement rates similar to surrounding prisms.

- For stable slopes, prism movement for the surficial materials are sub-parallel to the prism movement for the primary rock along the same cross-section.

- The occurrence of ongoing deformations in a pit slope is common and does not necessarily indicate that the slope is in the process of failing.

When prisms within the same pit slope retain higher movement rates than surrounding prisms this may provide an indication of potential instability in these areas.

\section{Acknowledgement}

The authors acknowledge Evolution Mining for allowing this paper to be published.

\section{References}

Hoek, E \& Diederichs, MS 2006, 'Empirical estimation of rock mass modulus', International Journal of Rock Mechanics and Mining Sciences, vol. 43, pp. 203-215.

Hoek, E, Kaiser, PK \& Bawden, WF 1995, Support of underground excavations in hard rock, Rotterdam, Balkema.

Itasca 2013, 3DEC, Three-Dimensional Distinct Element Code, version 5.0, Itasca Consulting Group.

Lee, M, Mollison, L, Campbell, A \& Litterbach, N 2010, 'Rock Stresses in the Australian Continental Tectonic Plate - Variability and Controls', in CY Chin, CI Massey, TJ McMorran, GM Pinches \& AL Williams (eds), Proceedings of the 11th IAEG Congress Geologically Active New Zealand, Auckland, CRC Press, Boca Raton.

Mercer, KG \& Stacey, TR 2008, 'A Generalized Time and Event Dependent Deformation Model for Unsupported Rock Slopes', in Y Potvin, J Carter, A Dyskin \& R Jeffery (eds), Proceedings of the First Southern Hemisphere International Rock Mechanics Symposium, Australian Centre for Geomechanics, Perth, pp. 481-492.

Sullivan, TD 1993, 'Understanding pit slope movements', in T Szwedzicki (ed.), Geotechnical Instrumentation and Monitoring in Open Pit and Underground Mining, Balkema, Rotterdam, pp. 435-445.

Sullivan, TD 2007, 'Hydromechanical Coupling and Pit Slope Movements', in Y Potvin (ed.), Slope Stability 2007, Australian Centre for Geomechanics, Perth, pp. 3-43.

Zavodni, ZM 2000, 'Time-Dependent Movements of Open-Pit Slopes', in WA Hustrulid, MK McCarter \& DJA Van Zyl (eds), Slope Stability in Surface Mining, SME, pp. 81-87. 